\title{
Phase I In Vitro Metabolic Profiling of the Synthetic Cannabinoid Receptor Agonists CUMYL-THPINACA and ADAMANTYL-THPINACA
}

\author{
Manuela Carla Monti (D), Eva Scheurer and Katja Mercer-Chalmers-Bender *D \\ Institute of Forensic Medicine, Department of Biomedical Engineering, University of Basel, \\ 4056 Basel, Switzerland; manuela.monti@unibas.ch (M.C.M.); eva.scheurer@unibas.ch (E.S.) \\ * Correspondence: katja.mercer-chalmers-bender@unibas.ch
}

Citation: Monti, M.C.; Scheurer, E.; Mercer-Chalmers-Bender, K. Phase I In Vitro Metabolic Profiling of the Synthetic Cannabinoid Receptor Agonists CUMYL-THPINACA and ADAMANTYL-THPINACA.

Metabolites 2021, 11, 470. https:// doi.org/10.3390/metabo11080470

Academic Editor: Cornelius Hess

Received: 18 June 2021

Accepted: 16 July 2021

Published: 21 July 2021

Publisher's Note: MDPI stays neutral with regard to jurisdictional claims in published maps and institutional affiliations.

Copyright: (C) 2021 by the authors. Licensee MDPI, Basel, Switzerland. This article is an open access article distributed under the terms and conditions of the Creative Commons Attribution (CC BY) license (https:/ / creativecommons.org/licenses/by/ $4.0 /)$.
Abstract: Synthetic cannabinoid receptor agonists (SCRAs) remain popular drugs of abuse. As many SCRAs are known to be mostly metabolized, in vitro phase I metabolic profiling was conducted of the two indazole-3-carboxamide SCRAs: CUMYL-THPINACA and ADAMANTYL-THPINACA. Both compounds were incubated using pooled human liver microsomes. The sample clean-up consisted of solid phase extraction, followed by analysis using liquid chromatography coupled to a high resolution mass spectrometer. In silico-assisted metabolite identification and structure elucidation with the data-mining software Compound Discoverer was applied. Overall, 28 metabolites were detected for CUMYL-THPINACA and 13 metabolites for ADAMATYL-THPINACA. Various mono-, di-, and tri-hydroxylated metabolites were detected. For each SCRA, an abundant and characteristic di-hydroxylated metabolite was identified as a possible in vivo biomarker for screening methods. Metabolizing cytochrome P450 isoenzymes were investigated via incubation of relevant recombinant liver enzymes. The involvement of mainly CYP3A4 and CYP3A5 in the metabolism of both substances were noted, and for CUMYL-THPINACA the additional involvement (to a lesser extent) of CYP2C8, CYP2C9, and CYP2C19 was observed. The results suggest that ADAMANTYL-THPINACA might be more prone to metabolic drug-drug interactions than CUMYL-THPINACA, when co-administrated with strong CYP3A4 inhibitors.

Keywords: synthetic cannabinoid receptor agonists; in vitro metabolism; high resolution mass spectrometry; Compound Discoverer

\section{Introduction}

Synthetic cannabinoid receptor agonists (SCRAs) are a prominent class within the world of new psychoactive substances (NPS). In recent years, SCRAs, together with synthetic cathinones, were the predominantly seized classes of NPS in Europe [1]. SCRAs encompass a large variety of structurally diverse compounds with binding affinities to the cannabinoid receptors 1 and 2 (CB1 and CB2). Particularly via interaction with CB1, most SCRAs present cannabimimetic effects similar to $\triangle 9$-tetrahydrocannabinol (THC), the major psychoactive compound in cannabis [2-4]. The typically higher binding affinities of SCRAs as full agonists at CB1 and CB2, when compared to THC, are attributed to the often-observed increased potency, but also toxicity, of these compounds. Nevertheless, data on the pharmacology and toxicity of SCRAs is still limited [2,5,6]. Several cases of severe intoxication, including lethal outcomes, have been associated with the intake of SCRAs, thus underlining the public health threat posed by these compounds [7-12].

SCRAs are classified based on their chemical structure [2]. In recent years, many indazole- and indole-carboxamide-derived SCRAs have been reported, with 5F-MDMBPINACA (5F-ADB), 5F-MDMB-PICA, and MDMB-4en-PINACA being frequently reported after detection in diverse formulations, ranging from shredded herbs that have been sprayed with SCRAs ("spice"), infused papers, e-liquids, and bulk powders [13-15]. Since 
the end of 2019, drug checking services in Switzerland have increasingly reported SCRAs fortified THC-low cannabis [16]. As these illicit products are generally sold as the nonaltered natural drug hemp, consumers unknowingly consuming SCRAs are clearly posed with an increased health threat. As the emergence of SCRAs on the drug market is constantly changing, as well as showing regional differences (for instance due to varying legal frameworks), it is important that analytical laboratories are constantly developing their analytical approach to SCRAs. Urine is a matrix that is often used for screening procedures in clinical and forensic toxicology due to favorable accessibility, higher concentrations of the substance of interest, and often longer detection windows when compared to blood. However, many SCRAs are known to be extensively metabolized, leading to a significant decrease or even lack of the parent compound in urine. As a consequence, metabolism studies identifying suitable target metabolites of NPS are inevitable [17-20].

CUMYL-THPINACA is classified as an indazole-3-carboxamide SCRA. A patent for CUMYL-THPINACA was issued in 2014 [21]. The cumyl-moiety is part of several SCRAs, as in, for example, CUMYL-BICA, 5F-CUMYL-PINACA, 5F-CUMYL-PICA, and CUMYL4CN-BINACA [22]. The metabolism of several cumyl-bearing SCRAs has been investigated before [23-26], therefore the obtained results for CUMYL-THPINACA expand the current knowledge on the metabolism of members of this diverse subgroup. Considering its activity, Asada et al. synthesized CUMYL-THPINACA, finding strong activity at CB1 and CB2 [27]. This was confirmed via radioligand binding studies conducted by Schoeder et al. that showed high binding affinities of CUMYL-THPINACA at both CB1 $\left(K_{i}=1.23 \pm 0.20 \mathrm{nM}\right)$ and CB2 $\left(K_{i}=1.38 \pm 0.86 \mathrm{nM}\right)$ [28]. Even though these data on the affinity and activity of CUMYL-THPINACA exist, metabolic profiling, resulting in suggested biomarkers for the detection of the consumption of CUMYL-THPINACA, has, to the best of our knowledge, not been conducted yet.

ADAMANTYL-THPINACA, also referred to as ATHPINACA, is structurally related to CUMYL-THPINACA and AKB48 (APINACA). The adamantyl-moiety can be connected to the rest of the molecule, yielding two positional isomers of ADAMANTYL-THPINACA, which are referred to as isomer 1 [N-(1-adamantyl)] and isomer 2 [(N-(2-adamantyl)]. This study focusses on isomer 1, if not further specified. ADAMANTYL-THPINACA was first reported by EMCDDA's Early Warning System after it appeared in Slovenia in 2015 [29], followed by Hungary in 2016 [30]. Recently, a study was published focusing on the metabolism of adamantyl-positional isomers of SCRAs, including first data on both isomers of ADAMANTYL-THPINACA. Metabolites were produced via incubation of pooled human liver microsomes (pHLM) and nine metabolites resulting from mono-, di-, and tri-hydroxylation were identified for isomer 1 of ADAMANTYL-THPINACA. Additionally, two glucuronidated metabolites were identified [31].

In this study, we present the phase I in vitro metabolic profiling of CUMYL-THPINACA and ADAMANTYL-THPINACA, applying two experimental set-ups. First, both SCRAs were incubated using $\mathrm{pHLM}$, resulting in structural elucidation and identification of potential in vivo biomarkers of the detected metabolites. The incubation of active pharmaceutical ingredients with pHLM, amongst other in vitro models (such as human hepatocytes), is an established procedure for initial characterization of human metabolism $[18,20,32]$ and therefore highly valuable for the study of SCRAs, for which information on the metabolism and suitable biomarkers is often lacking [20]. Metabolites as certified reference standards are often not available. Therefore, in vitro metabolism studies are a good alternative to incorporating metabolites into screening methods. Second, the cytochrome P450 enzymes (CYP) responsible for the phase I metabolism of the studied SCRAs were identified via incubation of a pallet of recombinant CYP isoforms ( $\mathrm{rCYP}$ ), thus expanding the present knowledge on the metabolism of ADAMANTYL-THPINACA as reported by Kadomura et al. [31]. Information on the metabolizing CYP isoforms gives the opportunity to predict the likelihood of metabolic drug-drug interactions or adverse events due to CYP polymorphisms [3337]. A study conducted by Holm et al. showed that CYP3A4 was mainly responsible for the biotransformation of AKB48, an SCRA structurally related to ADAMANTYL- 
THPINACA. Nevertheless, specific CYP isoforms involved in the metabolism of SCRAs are often understudied and have, so far, not been investigated for CUMYL-THPINACA or ADAMANTYL-THPINACA.

Due to the diversity and large numbers of NPS emerging on the drug market, the rapid identification of target metabolites for screening procedures is urgently needed. High-resolution mass spectrometry (HR-MS) data analysis software is gaining importance, as in silico-assisted workflows enable higher throughput and are able to markedly facilitate metabolite identification $[38,39]$. In this study, data analysis was assisted by the Compound Discoverer (Thermo Fisher Scientific, Reinach, Switzerland) software, which has already been proven helpful for metabolite identification and structure elucidation in previously published studies [38,40-43].

\section{Results and Discussion}

\subsection{Metabolite Identification for CUMYL-THPINACA and ADAMANTYL-THPINACA after} Incubation with $\mathrm{PHLM}$ and $\mathrm{rCY} P$

Functionality of the pHLM assay was assured by incubations of UR-144 (positive control) and subsequent detection of its $\mathrm{N}$-(5-hydroxypentyl) and N-pentanoic acid metabolites. Negative controls did not result in any metabolite signals.

CUMYL-THPINACA and ADAMANTYL-THPINACA were extensively metabolized, resulting in a substantial decrease of the parent compound in the incubation mixture. Several metabolites resulting from mono-, di-, tri-hydroxylation, desaturation (most likely via hydroxylation followed by dehydration), and carbonylation, as well as combinations thereof, were identified. A summary of all detected metabolites and artefacts, and the results obtained via rCYP incubation, are shown in in Tables 1 and 2 (for CUMYLTHPINACA) and Tables 3 and 4 (for ADAMANTYL-THPINACA).

\subsection{In-Source Water Loss of Metabolites}

As a consequence of using electrospray ionization (ESI), in-source-fragmentation processes may occur [39-42]. For example, the observed alleged metabolites, presenting a mass shift of $+13.9838 \mathrm{Da}$ in comparison to the parent compound, may result from either hydroxylation in combination with desaturation (e.g., di-hydroxylation followed by dehydration) or carbonylation. However, the corresponding signals may also arise from in-source water loss, resulting from the cleavage of aliphatic hydroxyl-groups (e.g., at the 4-methyl-tetrahydropyran- and adamantyl-moiety). In-source water loss was considered as likely, where (i) a hydroxylated metabolite was detected, exhibiting a hydroxyl group at a position predestined for in-source water loss, (ii) a co-eluting signal was identified, presenting a dehydration-specific mass shift of $-18.0153 \mathrm{Da}\left(-\mathrm{H}_{2} \mathrm{O}\right)$, and (iii) after fragmentation, when the type and position of biotransformation were identical for the hydroxylated metabolite and the alleged artefact. For example MC21, a metabolite produced by monohydroxylation at the 4-methyl-tetrahydropyran-moiety (i) was detected, but additionally a signal at the corresponding retention time (Rt) with mass shift of $[\mathrm{M}+\mathrm{H}]^{+}-18.0153 \mathrm{Da}$ was found (ii), which exhibits dehydration at the 4-methyl-tetrahydropyran-moiety (iii). Therefore, this signal was classified as an artefact (MCArt4).

The diversity in the hydroxylation patterns of metabolites, especially in cases of two or three concurrent hydroxylations, makes the evaluation of in-source processes highly complex. The observed results suggest that the susceptibility for in-source water loss considerably varies between aliphatic structures (e.g., adamantyl versus 4-methyl-tetrahydropyran). This becomes obvious when comparing the peak areas of genuine metabolites and the corresponding in-source artefacts. In the case of MA2 (hydroxylated at the adamantyl-moiety) the corresponding artefact (MAArt1) showed a 6.8 times higher signal than observed for MA2 itself. In comparison, MC21 (hydroxylated at the 4-methyl-tetrahydropyran-moiety) exhibited an in-source dehydration signal of roughly the same intensity as that observed for MC21. Additionally, positional isomers of hydroxylations within a moiety led to varying levels of observed water loss. For instance, when investigating the metabolite cluster 
MC8a-e (consisting of several co-eluting di-hydroxylated metabolites, bearing a hydroxylgroup at the 4-methyl-tetrahydropyran-moiety), in-source water loss varied from excessive (artefact signal [MCArt2a-b] > metabolite signal) to not detectable.

In this study, several hydroxylated metabolites of CUMYL-THPINACA and one of ADAMANTYL-THPINACA were prone to in-source dehydration, in most cases attributable to the instability of the hydroxylated 4-methyl-tetrahydropyran-moiety. This most likely resulted in the identification of several artefacts that are discussed in the corresponding chapters referring to the genuine metabolites. In addition, several signals were detected lacking a hydroxylated counterpart, therefore not meeting the above-stated criteria for in-source water loss-they were thus classified as genuine metabolites produced by hydroxylation and desaturation (MC3, MC6, MC12, MC17, MA3, MA8, MA11) or carbonylation (MC13, MC15, MC18, MC20, MC22, MA13, MA10). However, the possibility remains, that the hydroxylated original metabolite was prone to complete in-source water loss, i.e., the original parent ion was no longer detectable. In the context of analytics and the herein presented aims, the focus of this study lies in the identification of suitable biomarkers, which may include highly abundant artefacts resulting from true metabolites. As in-source fragmentation is often seen as an unwanted ESI byproduct, it has also been proposed that in-source-fragment information can improve metabolite identification [44]. However, it must be kept in mind, that the occurrence of in-source-fragmentation processes may also depend on the instrument used, instrument configurations, and ESI conditions.

\subsection{Metabolic Profiling of CUMYL-THPINACA}

The fragmentation of CUMYL-THPINACA resulted in three diagnostic fragments at $m / z 119.0855$, representing the cumyl-moiety, $m / z 260.1394$, referring to the unaltered 1-(tetrahydropyranyl-4-methyl)-indazole-3-carboxamide structure, and $m / z 243.1128$, representing the 1-(tetrahydropyranyl-4-methyl)-indazole-3-acylium-ion. A total of three monohydroxylated (MC19a-b, MC21), eight di-hydroxylated (MC1, MC8a-e, MC14, MC16), and eight tri-hydroxylated (MC2a-b, MC4, MC5, MC7, MC9, MC10, MC11) metabolites were detected (see Table 1). The di-hydroxylated metabolite MC16, presenting with highest peak areas in the conducted experiments, is suggested as a suitable target in screening procedures. Additional minor metabolites were produced via either hydroxylation with concurrent dehydration, referred to as mono-/di-hydroxylated and desaturated metabolites, or carbonylation. In this context, two mono-hydroxylated and desaturated metabolites (MC12, MC17) and two di-hydroxylated and desaturated metabolites (MC3, MC6) were identified. Finally, carbonylation led to the production of one metabolite (MC22) and mono-hydroxylation in combination with carbonylation resulted in four metabolites (MC13, MC15, MC18, MC20). In-source water loss could not be ruled out for some metabolites; thus, these signals were classified as artefacts (MCArt1, MCArt2a-b, MCArt4, MCArt5). Through conduction of a derivatization experiment, employing iodomethane as the methylating agent, the location of the hydroxyl-groups could be narrowed down to the indazole-core. The main site for biotransformation in regard to number of individual metabolites as well as when considering the most abundant metabolites was the 4-methyl-tetrahydropyran-moiety, while oxidation of the cumyl-moiety was less often observed. There are several other studies investigating the metabolism of SCRAs containing a cumyl-moiety $[22,23,26]$. These aforementioned studies also concluded that the cumyl-moiety was not the main site of metabolism. A chromatogram showing the mass traces of all metabolites is depicted in Figure 1 and the proposed metabolic pathway of CUMYL-THPINACA is visualized in Figure 2. MS ${ }^{2}$ spectra of CUMYL-THPINACA and the three most abundant metabolites, including proposed fragments, are shown in Figure 3. 


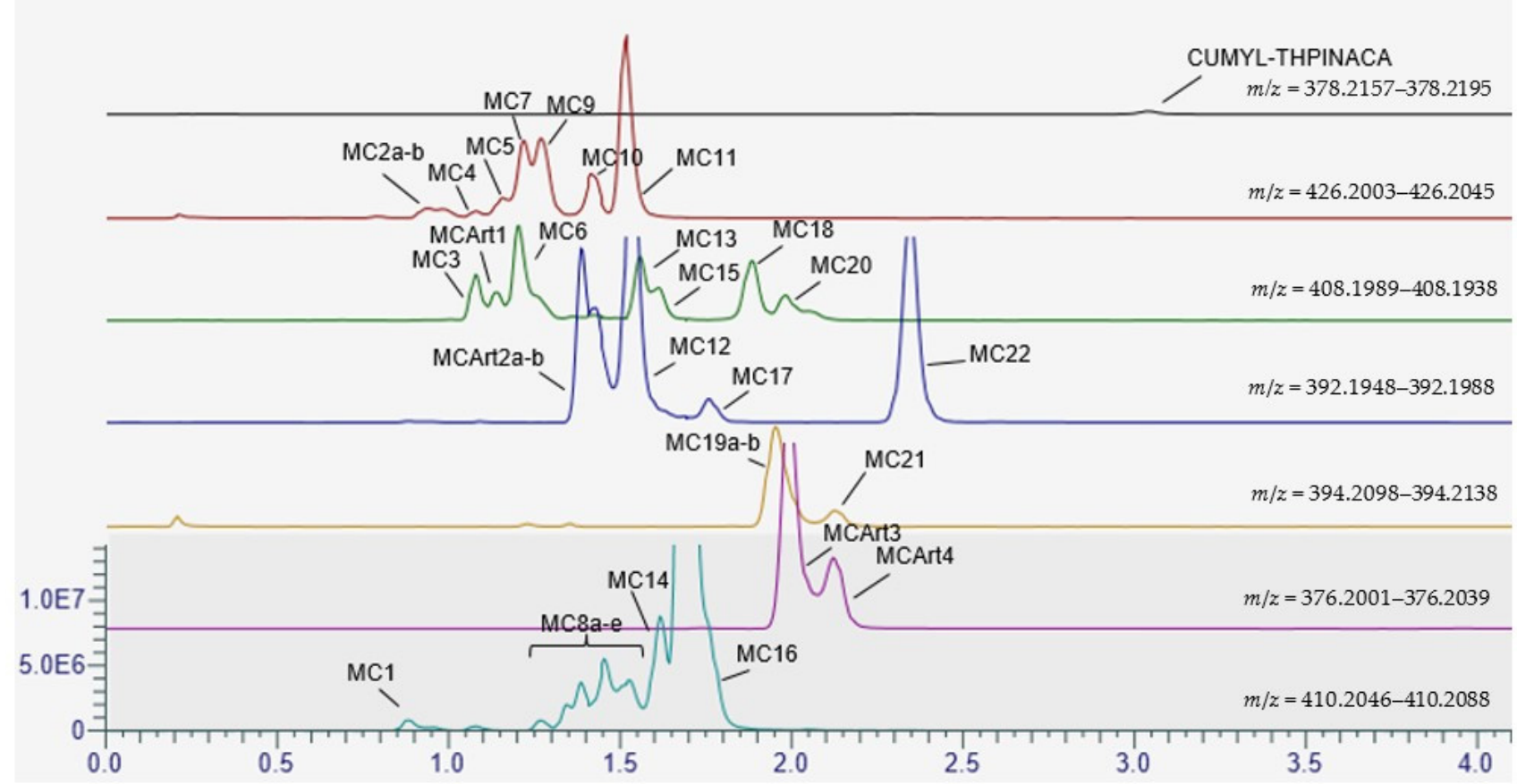

Figure 1. Chromatogram showing the mass traces of the detected metabolites (and artefacts) of CUMYL-THPINACA after 2 $\mathrm{h}$ of incubation. The traces are normalized globally, with a maximum at $12 \%$ of the base peak (MC16).

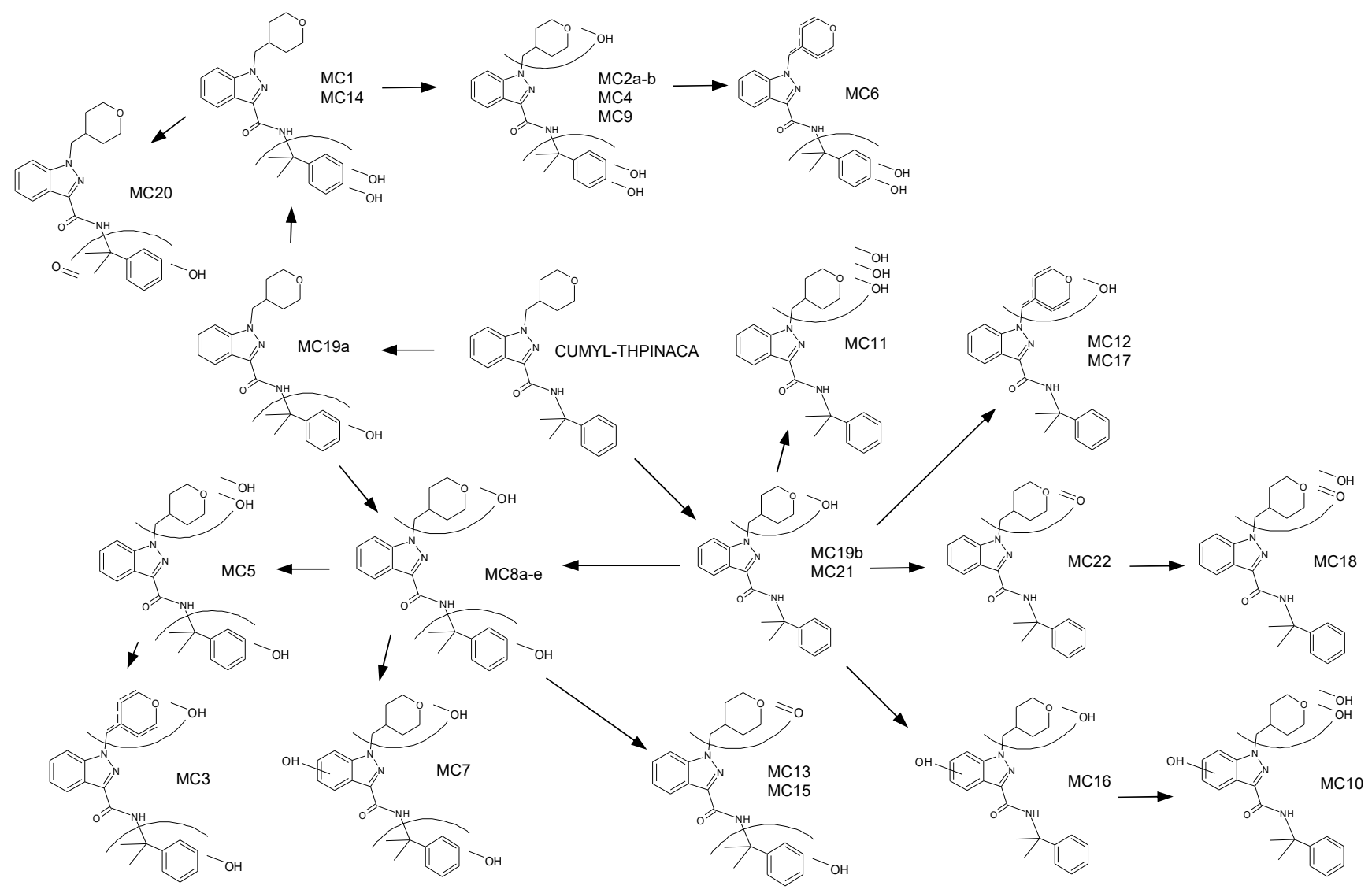

Figure 2. Proposed metabolic pathway for CUMYL-THPINACA. 

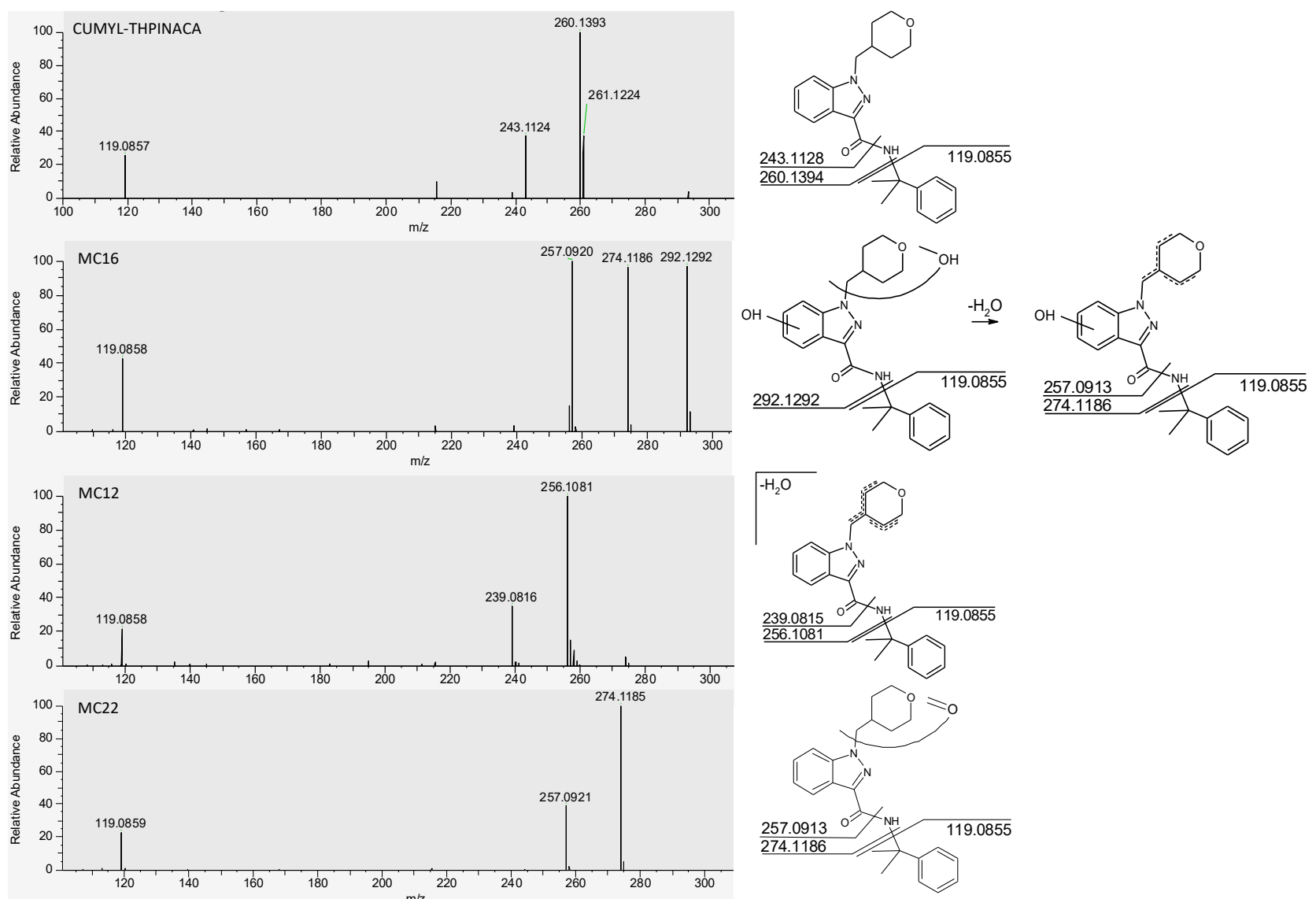

Figure 3. $\mathrm{MS}^{2}$ spectra of CUMYL-THPINACA and its three most abundant metabolites (MC12, MC16, and MC22, shown in order of decreasing intensity). The proposed fragments leading to the respective signals are shown on the right.

Table 1. Summary of all detected metabolites and the two detected artefacts of CUMYL-THPINACA (listed in the order of the observed retention times) with suggested biotransformations, chemical formulas, calculated $[\mathrm{M}+\mathrm{H}]^{+}$of the parent ions with associated product ions $(\mathrm{m} / z)$, mass error ( $\mathrm{ppm})$, retention times (Rt), areas after $2 \mathrm{~h}$ of incubation using pHLM and ranking (highest to lowest abundancy).

\begin{tabular}{|c|c|c|c|c|c|c|c|}
\hline ID & Biotransformation & Formula & $\begin{array}{l}{[\mathbf{M}+\mathbf{H}]^{+}} \\
\text {Productions } \\
\quad(m / z)\end{array}$ & $\begin{array}{c}\text { Mass } \\
\text { Error (ppm) }\end{array}$ & $\underset{(\min )}{\mathbf{R t}}$ & $\begin{array}{c}\text { Area } \\
(n=2)\end{array}$ & Rank \\
\hline MC1 & di-hydroxylation at cumyl & $\mathrm{C}_{23} \mathrm{H}_{28} \mathrm{~N}_{3} \mathrm{O}_{4}$ & $\begin{array}{l}410.2074 \\
259.1077 \\
151.0754\end{array}$ & 0.4 & 0.89 & $3.0 \times 10^{6}$ & 21 \\
\hline $\mathrm{MC} 2 \mathrm{a}-\mathrm{b}$ & $\begin{array}{l}\text { di-hydroxylation at cumyl, } \\
\text { mono-hydroxylation at } \\
\text { 4-methyl-tetrahydropyran }\end{array}$ & $\mathrm{C}_{23} \mathrm{H}_{28} \mathrm{~N}_{3} \mathrm{O}_{5}$ & $\begin{array}{l}426.2023 \\
408.1918 \\
259.1077 \\
151.0754\end{array}$ & 0.4 & $\begin{array}{l}\text { a: } 0.90 \\
\text { b: } 0.99\end{array}$ & $3.9 \times 10^{6}$ & 19 \\
\hline MC3 & $\begin{array}{l}\text { mono-hydroxylation at } \\
\text { cumyl, mono-hydroxylation } \\
\text { and desaturation at } \\
\text { 4-methyl-tetrahydropyran }\end{array}$ & $\mathrm{C}_{23} \mathrm{H}_{28} \mathrm{~N}_{3} \mathrm{O}_{5}$ & $\begin{array}{l}408.1918 \\
256.1081 \\
135.0804\end{array}$ & -0.1 & 1.08 & $8.00 \times 10^{6}$ & 14 \\
\hline MC4 & $\begin{array}{l}\text { di-hydroxylation at cumyl, } \\
\text { mono-hydroxylation at } \\
\text { 4-methyl-tetrahydropyran }\end{array}$ & $\mathrm{C}_{23} \mathrm{H}_{28} \mathrm{~N}_{3} \mathrm{O}_{5}$ & $\begin{array}{l}426.2023 \\
408.1918 \\
259.1077 \\
151.0754\end{array}$ & -0.2 & 1.08 & $1.1 \times 10^{6}$ & 22 \\
\hline
\end{tabular}


Table 1. Cont.

\begin{tabular}{|c|c|c|c|c|c|c|c|}
\hline ID & Biotransformation & Formula & $\begin{array}{l}{[\mathrm{M}+\mathrm{H}]^{+}} \\
\text {Productions } \\
\quad(m / z)\end{array}$ & $\begin{array}{c}\text { Mass } \\
\text { Error (ppm) }\end{array}$ & $\underset{(\min )}{\mathrm{Rt}}$ & $\begin{array}{c}\text { Area } \\
(n=2)\end{array}$ & Rank \\
\hline MCArt1 & In-source water loss of MC5 & $\mathrm{C}_{23} \mathrm{H}_{28} \mathrm{~N}_{3} \mathrm{O}_{5}$ & $\begin{array}{l}408.1918 \\
256.1081 \\
135.0804\end{array}$ & 0.4 & 1.16 & $4.5 \times 10^{6}$ & - \\
\hline MC5 & $\begin{array}{l}\text { mono-hydroxylation at } \\
\text { cumyl, di-hydroxylation at } \\
\text { 4-methyl-tetrahydropyran }\end{array}$ & $\mathrm{C}_{23} \mathrm{H}_{28} \mathrm{~N}_{3} \mathrm{O}_{5}$ & $\begin{array}{l}426.2023 \\
274.1186 \\
256.1081 \\
135.0804\end{array}$ & 0.8 & 1.19 & $3.7 \times 10^{6}$ & 20 \\
\hline MC6 & $\begin{array}{l}\text { di-hydroxylation at cumyl, } \\
\text { desaturation at } \\
\text { 4-methyl-tetrahydropyran }\end{array}$ & $\mathrm{C}_{23} \mathrm{H}_{28} \mathrm{~N}_{3} \mathrm{O}_{5}$ & $\begin{array}{l}408.1918 \\
258.1237 \\
151.0754\end{array}$ & -0.3 & 1.20 & $2.3 \times 10^{7}$ & 7 \\
\hline MC7 & $\begin{array}{c}\text { mono-hydroxylation at } \\
\text { cumyl, mono-hydroxylation } \\
\text { at indazole, } \\
\text { mono-hydroxylation at } \\
\text { 4-methyl-tetrahydropyran }\end{array}$ & $\mathrm{C}_{23} \mathrm{H}_{28} \mathrm{~N}_{3} \mathrm{O}_{5}$ & $\begin{array}{l}426.2023 \\
292.1292 \\
274.1186 \\
257.0913 \\
135.0804\end{array}$ & -0.6 & 1.23 & $1.6 \times 10^{7}$ & 10 \\
\hline MC8a-e & $\begin{array}{l}\text { mono-hydroxylation at } \\
\text { cumyl and } \\
\text { mono-hydroxylation at } \\
\text { 4-methyl-tetrahydropyran }\end{array}$ & $\mathrm{C}_{23} \mathrm{H}_{28} \mathrm{~N}_{3} \mathrm{O}_{4}$ & $\begin{array}{l}410.2074 \\
258.1237 \\
241.0972 \\
135.0804\end{array}$ & -1.3 & $\begin{array}{l}\text { a: } 1.28 \\
\text { b: } 1.35 \\
\text { c: } 1.39 \\
\text { d: } 1.46 \\
\text { e: } 1.53\end{array}$ & $4.4 \times 10^{7}$ & 4 \\
\hline MC9 & $\begin{array}{l}\text { di-hydroxylation at cumyl, } \\
\text { mono-hydroxylation at } \\
\text { 4-methyl-tetrahydropyran }\end{array}$ & $\mathrm{C}_{23} \mathrm{H}_{28} \mathrm{~N}_{3} \mathrm{O}_{5}$ & $\begin{array}{l}426.2023 \\
258.1237 \\
151.0754\end{array}$ & -0.6 & 1.27 & $1.9 \times 10^{7}$ & 9 \\
\hline MCArt2a-b & $\begin{array}{l}\text { In-source water loss } \\
\text { MC8a-e }\end{array}$ & $\mathrm{C}_{23} \mathrm{H}_{26} \mathrm{~N}_{3} \mathrm{O}_{3}$ & $\begin{array}{l}392.1969 \\
258.1237 \\
241.0972 \\
135.0804\end{array}$ & -1.7 & $\begin{array}{l}\text { a: } 1.39 \\
\text { b: } 1.44\end{array}$ & $5.5 \times 10^{7}$ & - \\
\hline MC10 & $\begin{array}{l}\text { di-hydroxylation at } \\
\text { 4-methyl-tetrahydropyran, } \\
\text { mono-hydroxylation at } \\
\text { indazole }\end{array}$ & $\mathrm{C}_{23} \mathrm{H}_{28} \mathrm{~N}_{3} \mathrm{O}_{5}$ & $\begin{array}{c}426.2023 \\
308.1241 \\
290.1135 \\
272.103 \\
119.0855\end{array}$ & -0.7 & 1.42 & $9.1 \times 10^{6}$ & 13 \\
\hline MC11 & $\begin{array}{c}\text { tri-hydroxylation at } \\
\text { 4-methyl-tetrahydropyran }\end{array}$ & $\mathrm{C}_{23} \mathrm{H}_{28} \mathrm{~N}_{3} \mathrm{O}_{5}$ & $\begin{array}{c}426.2023 \\
308.1241 \\
290.1135 \\
272.103 \\
254.0924 \\
119.0855\end{array}$ & -0.5 & 1.51 & $3.8 \times 10^{7}$ & 5 \\
\hline MC12 & $\begin{array}{l}\text { mono-hydroxylation and } \\
\text { desaturation at } \\
\text { 4-methyl-tetrahydropyran }\end{array}$ & $\mathrm{C}_{23} \mathrm{H}_{26} \mathrm{~N}_{3} \mathrm{O}_{3}$ & $\begin{array}{l}392.1969 \\
256.1081 \\
239.0815\end{array}$ & -1.6 & 1.54 & $7.8 \times 10^{7}$ & 2 \\
\hline MC13 & $\begin{array}{l}\text { mono-hydroxylation at } \\
\text { cumyl, carbonylation at } \\
\text { 4-methyl-tetrahydropyran }\end{array}$ & $\mathrm{C}_{23} \mathrm{H}_{28} \mathrm{~N}_{3} \mathrm{O}_{5}$ & $\begin{array}{l}408.1918 \\
274.1186 \\
257.0913 \\
135.0804\end{array}$ & -1.2 & 1.56 & $1.1 \times 10^{7}$ & 12 \\
\hline MC14 & di-hydroxylation at cumyl & $\mathrm{C}_{23} \mathrm{H}_{28} \mathrm{~N}_{3} \mathrm{O}_{4}$ & $\begin{array}{l}410.2074 \\
260.1394 \\
151.0754\end{array}$ & -1.1 & 1.62 & $2.3 \times 10^{7}$ & 8 \\
\hline
\end{tabular}


Table 1. Cont.

\begin{tabular}{|c|c|c|c|c|c|c|c|}
\hline ID & Biotransformation & Formula & $\begin{array}{l}{[\mathrm{M}+\mathrm{H}]^{+}} \\
\text {Productions } \\
\quad(\mathrm{m} / \mathrm{z})\end{array}$ & $\begin{array}{c}\text { Mass } \\
\text { Error (ppm) }\end{array}$ & $\begin{array}{c}\text { Rt } \\
(\min )\end{array}$ & $\begin{array}{c}\text { Area } \\
(n=2)\end{array}$ & Rank \\
\hline MC15 & $\begin{array}{l}\text { mono-hydroxylation at } \\
\text { cumyl, carbonylation at } \\
\text { 4-methyl-tetrahydropyran }\end{array}$ & $\mathrm{C}_{23} \mathrm{H}_{28} \mathrm{~N}_{3} \mathrm{O}_{5}$ & $\begin{array}{l}408.1918 \\
274.1186 \\
257.0913 \\
135.0804\end{array}$ & -0.1 & 1.62 & $6.3 \times 10^{6}$ & 16 \\
\hline MC16 & $\begin{array}{l}\text { mono-hydroxylation at } \\
\text { 4-methyl-tetrahydropyran, } \\
\text { mono-hydroxylation at } \\
\text { indazole }\end{array}$ & $\mathrm{C}_{23} \mathrm{H}_{28} \mathrm{~N}_{3} \mathrm{O}_{4}$ & $\begin{array}{l}410.2074 \\
292.1292 \\
274.1186 \\
257.0913 \\
119.0855\end{array}$ & -1.3 & 1.69 & $3.4 \times 10^{8}$ & 1 \\
\hline MC17 & $\begin{array}{l}\text { mono-hydroxylation and } \\
\text { desaturation at } \\
\text { 4-methyl-tetrahydropyran }\end{array}$ & $\mathrm{C}_{23} \mathrm{H}_{26} \mathrm{~N}_{3} \mathrm{O}_{3}$ & $\begin{array}{l}392.1969 \\
256.1081 \\
239.0815 \\
119.0855\end{array}$ & -0.9 & 1.81 & $5.6 \times 10^{6}$ & 17 \\
\hline MC18 & $\begin{array}{l}\text { mono-hydroxylation and } \\
\text { carbonylation at } \\
\text { 4-methyl-tetrahydropyran }\end{array}$ & $\mathrm{C}_{23} \mathrm{H}_{28} \mathrm{~N}_{3} \mathrm{O}_{5}$ & $\begin{array}{c}408.1918 \\
290.1135 \\
273.087 \\
272.103 \\
119.0855\end{array}$ & -0.2 & 1.88 & $1.3 \times 10^{7}$ & 11 \\
\hline \multirow[t]{2}{*}{ MC19a-b } & $\begin{array}{l}\text { a: mono-hydroxylation at } \\
\text { cumyl }\end{array}$ & $\begin{array}{c}\mathrm{C}_{23} \mathrm{H}_{28} \mathrm{~N}_{3} \mathrm{O}_{3} \\
\text { a: }\end{array}$ & $\begin{array}{l}394.2118 \\
135.0804 \\
260.1394 \\
243.1128\end{array}$ & 1.4 & 1.99 & $3.0 \times 10^{7}$ & 6 \\
\hline & $\begin{array}{l}\text { b: mono-hydroxylation at } \\
\text { 4-methyl-tetrahydropyran }\end{array}$ & b: & $\begin{array}{l}276.1343 \\
119.0855\end{array}$ & & & & \\
\hline MCArt3 & In-source water loss $\mathrm{MC} 19 \mathrm{~b}$ & $\mathrm{C}_{23} \mathrm{H}_{25} \mathrm{~N}_{3} \mathrm{O}_{2}$ & $\begin{array}{l}376.2020 \\
258.1237 \\
119.0855\end{array}$ & -0.7 & 2.03 & $1.5 \times 10^{7}$ & - \\
\hline MC20 & $\begin{array}{l}\text { mono-hydroxylation and } \\
\text { carbonylation at cumyl }\end{array}$ & $\mathrm{C}_{23} \mathrm{H}_{28} \mathrm{~N}_{3} \mathrm{O}_{5}$ & $\begin{array}{l}408.1918 \\
260.1394 \\
243.1128 \\
149.1660\end{array}$ & -0.1 & 1.98 & $7.0 \times 10^{6}$ & 15 \\
\hline MC21 & $\begin{array}{l}\text { mono-hydroxylation at } \\
\text { 4-methyl-tetrahydropyran }\end{array}$ & $\mathrm{C}_{23} \mathrm{H}_{28} \mathrm{~N}_{3} \mathrm{O}_{3}$ & $\begin{array}{l}394.2118 \\
258.1237 \\
119.0855\end{array}$ & 1.4 & 2.15 & $4.4 \times 10^{6}$ & 18 \\
\hline MCArt4 & In-source water loss MC21 & $\mathrm{C}_{23} \mathrm{H}_{25} \mathrm{~N}_{3} \mathrm{O}_{2}$ & $\begin{array}{l}376.2020 \\
258.1237 \\
119.0855\end{array}$ & -0.5 & 2.17 & $4.7 \times 10^{6}$ & - \\
\hline MC22 & $\begin{array}{c}\text { carbonylation at } \\
\text { 4-methyl-tetrahydropyran }\end{array}$ & $\mathrm{C}_{23} \mathrm{H}_{26} \mathrm{~N}_{3} \mathrm{O}_{3}$ & $\begin{array}{l}392.1969 \\
274.1186 \\
257.0913 \\
119.0855\end{array}$ & -1.3 & 2.39 & $5.0 \times 10^{7}$ & 3 \\
\hline & MYL-THPINACA & $\mathrm{C}_{23} \mathrm{H}_{27} \mathrm{~N}_{3} \mathrm{O}_{2}$ & $\begin{array}{l}378.2176 \\
260.1394 \\
243.1128 \\
119.0855\end{array}$ & 0.1 & 3.07 & $8.9 \times 10^{5}$ & - \\
\hline
\end{tabular}

\subsubsection{Mono-Hydroxylation}

MC19a is mono-hydroxylated at the cumyl-moiety, as a fragment at $m / z 135.0804$ was detected. For M19b and MC21, mono-hydroxylation at the 1-(tetrahydropyranyl-4methyl)-indazole-3-carboxamide structure was detected instead $(m / z 276.1343)$. Due to the observation of in-source dehydration (MCArt3 and MCArt4), and as derivatization did not 
alter the signals of MC19b and MC21, the location of the hydroxyl groups are suggested to be located at the unsaturated 4-methyl-tetrahydropyran-moiety. MCArt3 and MCArt4 are signals matching the criteria defined in chapter 2.2, and thus are classified as artefacts resulting from in-source dehydration of MC19b and MC21. Fragmentation of MCArt3 and MCArt4 showed desaturation at the 4-methyl-tetrahydropyran-moiety $(\mathrm{m} / \mathrm{z} 258.1237)$, which corresponds to the location of mono-hydroxylation of the co-eluting metabolites MC19b and MC21.

\subsubsection{Di-Hydroxylation}

The most abundant metabolite after $2 \mathrm{~h}$ of incubation was the di-hydroxylated metabolite MC16. For MC16, the unaltered cumyl-moiety was detected. As a dehydration reaction was identified during fragmentation, resulting in a fragment at $m / z 274.1186$, it was concluded that the second hydroxyl-group is located at the 4-methyl-tetrahydropyran-moiety. The location of the second hydroxyl-group at the indazole-core was verified after derivatization. When fragmenting the proposed product of methylation of MC16 at $\mathrm{m} / \mathrm{z} 424.2231$ (mass shift of 14.0157 Da), a specific fragment corresponding to the 1-(tetrahydropyranyl-4methyl)-indazole-3-carboxamide-moiety which had been di-hydroxylated and methylated, was detected at $m / z$ 306.1448.

MC1, MC8a-e, and MC16 are additional metabolites resulting from di-hydroxylation. MC1 is produced via di-hydroxylation at the cumyl-moiety, indicated by a fragment at $m / z$ 151.0754. Several isomers were detected arising from concurrent mono-hydroxylation at the cumyl-moiety and the 1-(tetrahydropyranyl-4-methyl)-indazole-3-carboxamidemoiety, resulting in the metabolite cluster MC8a-e. As the fragment at $m / z 258.1237$ was found throughout (produced via water loss from the 4-methyl-tetrahydropyran-moiety), the hydroxyl-group of the metabolites MC8a-e were concluded to be located at the 4methyl-tetrahydropyran-moiety. Co-eluted with the metabolite cluster MC8a-e, MCArt2a$b$ (consisting of two fused peaks), was detected. After fragmentation of MCArt2a-b, the location of one hydroxyl-group was identified at the cumyl-moiety and desaturation was found at the 4-methyl-tetrahydropyran-moiety. Due to the matching type and location of the biotransformation between the original metabolites MC8a-e and MCArt2a-b, the origin of the signal leading to MCArt2a-b was defined as in-source water loss. Finally, MC14 is di-hydroxylated at the di-hydroxylated cumyl-moiety, as the diagnostic fragment at $m / z 151.0754$ was identified.

\subsubsection{Mono-Hydroxylation and Additional Desaturation and Carbonylation}

MC12, MC17, and MC22 are all metabolites sharing the parent ion at $m / z$ 392.1969. As no co-eluting di-hydroxylated metabolites exhibiting the same patterns were detectable (considering the type and location of biotransformation), in-source water loss as the origin of the corresponding signals was ruled out for these metabolites. MC12 and MC17 presented a fragment at $m / z 256.1081$ that resulted from the dehydration of the already desaturated 1-(tetrahydropyranyl-4-methyl)-indazole-3-carboxamide-moiety. Due to the observed desaturation, MC14 and MC19 were classified as mono-hydroxylated and desaturated at the 4-methyl-tetrahydropyran-moiety. The absence of phenolic hydroxyl groups was confirmed via derivatization experiments, as no signal decline of the parent ion was observed. MC22 did not present a dehydration reaction during fragmentation as only the fragments with $m / z 274.1186$ (desaturated 1-(tetrahydropyranyl-4-methyl)indazole-3-carboxamide structure) and $m / z 257.09134$ (acylium-ion after cleavage of the $\mathrm{C}-\mathrm{N}$ bond) were detected. Therefore, M22 was concluded to be carbonylated at the 4methyl-tetrahydropyran-moiety.

\subsubsection{Tri-Hydroxylation}

MC2a-b and MC4 are di-hydroxylated at the cumyl-moiety, as verified by detection of the fragment at $m / z$ 151.0754. MC2a-b and MC4 also present a fragment at $m / z 408.1918$ as a result of water loss during fragmentation of the otherwise intact structure. Due to the 
observed water loss, the location of the one hydroxyl group is situated at the 4-methyltetrahydropyran-moiety. MC5 was observed to be mono-hydroxylated at the cumyl-moiety, showing the diagnostic fragment at $m / z$ 135.0804. The additional fragment at $m / z 256.1081$, resulting from two dehydration reactions of the di-hydroxylated 1-(tetrahydropyranyl-4methyl)-indazole-3-carboxamide structure, verifies the positions of the two other hydroxyl groups at the 4-methyl-tetrahydropyran-moiety. In-source water loss of MC5, leading to the signal of MCArt1, could not be ruled out, due to the proximity of MC5 and the observed signal of MCArt1, which also has one hydroxyl-group at the cumyl-moiety $(m / z 135.0804)$ but is hydroxylated and additionally desaturated at the tetrahydropyran-moiety. Thus, MCArt1 was defined as a possible artefact.

Mono-hydroxylation at the cumyl-moiety was also observed for MC7. As for MC7, only one dehydration reaction was detected, indicated by the fragment at $m / z 274.1186$. Observed fragments for MC7 indicated mono-hydroxylation at the cumyl-moiety, the indazole-core, and at the 4-methyl-tetrahydropyran-moiety. This was also confirmed via the derivatization experiment, as the methylated product of $\mathrm{MC} 7$ was detected, presenting a diagnostic fragment at $m / z 306.1448$, which represents the di-hydroxylated and methylated 1-(tetrahydropyranyl-4-methyl)-indazole-3-carboxamide-moiety. MC9 is di-hydroxylated at the cumyl-moiety, as shown by the fragment at $m / z 151.0754$. Additionally, a fragment at $\mathrm{m} / z 258.1237$ was detected, which was the dehydration product of the 1-(tetrahydropyranyl4-methyl)-indazole-3-acylium-ion, thus indicating the location of the third hydroxyl group at the 4-methyl-tetrahydropyran-moiety. MC10 is suggested to be di-hydroxylated at the 4methyl-tetrahydropyran-moiety, but additionally mono-hydroxylated at the indazole-core. Further, an ion corresponding to the product of tri-hydroxylation and methylation of MC10 at $m / z 440.2180$ was detected after derivatization. Fragmentation of this methylated metabolite produced a diagnostic ion at $m / z$ 322.1397, referring to the methylated tri-hydroxylated 1-(tetrahydropyranyl-4-methyl)-indazole-3-acylium-ion, and thus verifying the location of one hydroxyl group at the unsaturated indazole-region. MC11 is tri-hydroxylated at the 1(tetrahydropyranyl-4-methyl)-indazole-3-carboxamide structure, as the fragment standing for the tri-hydroxylated 1-(tetrahydropyranyl-4-methyl)-indazole-3-carboxamide-moiety $(\mathrm{m} / z$ 308.1241) was detected. Additionally, this moiety produced further fragments, after one $(m / z 290.1135)$, two $(m / z 272.1030)$, and three dehydrations $(m / z 254.0924)$. Derivatization did not result in a decline of the MC11 signal, thus confirming the location of all three hydroxyl-groups at the unsaturated 4-methyl-tetrahydropyran-moiety.

\subsubsection{Mono-Hydroxylation and Additional Desaturation and Carbonylation}

MC3 is most likely formed via metabolic tri-hydroxylation (MC5) and concurrent dehydration, resulting in a di-hydroxylated and desaturated molecule. MC3 presented a fragment at $m / z$ 135.0804, which represents the mono-hydroxylated cumyl-moiety. The desaturation reaction and the second hydroxyl group are located at the 4-methyl-tetrahydropyranmoiety, as the fragment at $m / z 256.1081$ was detected-resulting from additional dehydration of this moiety. For MC6, the location of both hydroxyl-groups was found to be at the cumyl-moiety, as a fragment at $m / z 151.0754$ was detected. An additionally observed fragment at $m / z 258.1237$ was attributed to the desaturated 1-(tetrahydropyranyl-4-methyl)indazole-3-acylium-ion.

MC13 and MC15 are classified as mono-hydroxylated and carbonylated metabolites. With the diagnostic ion at $m / z 135.0804$, both are identified as to be mono-hydroxylated at the cumyl-moiety. Due to the lack of the dehydration reaction during occurring fragmentation, it is suggested that MC13 and MC15 are therefore carbonylated at the 4-methyltetrahydropyran-moiety. Mono-hydroxylation in combination with carbonylation was also observed for MC18. Due to the presence of the fragment at $m / z 119.0855$, and as MC18 was not methylated during derivatization, proving the absence of phenolic hydroxyl groups, it is assumed that hydroxylation and carbonylation must be located at the 4-methyl-tetrahydropyran-moiety. The fragment at $\mathrm{m} / \mathrm{z} 290.1135$ represents the monohydroxylated and carbonylated 1-(tetrahydropyranyl-4-methyl)-indazole-3-carboxamide 
structure. The fragment at $m / z 272.1030$ is produced by additional dehydration and a fragment at $m / z 273.087$ results from nitrogen cleavage. MC20 presented two diagnostic ions at $m / z 260.1394$ and $m / z 243.1128$, representing the unaltered 1-(tetrahydropyranyl4-methyl)-indazole-3-carboxamide-moiety. The fragment at $m / z 149.0597$ represents the cumyl-moiety that has been mono-hydroxylated and carbonylated. With the methylated product of MC21, the location of the hydroxyl was assigned at the phenyl-ring of the cumyl-moiety. In-source water loss, resulting in an additional signal associated with MC3, MC6, MC13, MC17, MC18, and MC20, was not further considered, due to the lack of corresponding tri-hydroxylated metabolites in the respective elution windows. The observed later elution of metabolites MC18 and MC20 was in concordance with the suggested carbonylation, as this biotransformation would result in less polar metabolites compared to the product of di-hydroxylation and desaturation.

\subsubsection{Identification of the Primarily Involved CYP Isoenzymes}

The results obtained showed that CYP3A4 and CYP3A5 are primarily involved in the metabolism of CUMYL-THPINACA, followed by CYP2D6, CYP2C8, and, to a much lesser extent, by CYP2C19. The involvement of CYP2C9, CYP1A2, and CYP2B6 was also observed. Signals at the retention times of MCArt3 and MCArt4, presenting an area ratio (peak area/internal standard (ISTD) area) of $<0.1$, were detected in the negative control as well as in the incubation mixture of CYP2E1 and CYP2A6. As these were the only signals detected for CYP2E1 and CYP2A6, it suggests that CYP2E1 and CYP2A6 did not show any metabolic activity for CUMYL-THPINACA. Two metabolites (MC4 and MC5), which were observed after incubation using pHLM, could not be detected after incubation with rCYP (tested with different incubation times), most likely due to these metabolites being produced via a more complex pathway; the involvement of a combination of different CYP; or at concentration levels below the limit of detection. These results are summarized in Table 2.

CYP3A4 is an important CYP isoform with regard to abundancy in the human liver as well as the majority of drugs being known to be substrates of CYP3A4. Overall, due to the primary involvement of CYP3A4, drug-drug interactions may be observable in combination with strong CYP3A4 inhibitors (e.g., azole-antifungals) [45]. Nevertheless, due to the involvement of further CYP isoforms (e.g., CYP2D6, CYP2C8, and CYP2C19), this risk is most likely reduced.

Table 2. Results of the incubation of CUMYL-THPINACA with rCYP. Listed area ratios (absolute peak are (metabolite)/absolute peak area (ISTD)) are classified as follows: $(+):<0.1,+: \geq 0.1-\leq 1,++:>1-\leq 5,+++:>$. Where the negative control contained trace amounts of metabolites in a comparable amount, as in the samples after incubation, the result is marked as: $(+)$ *.

\begin{tabular}{|c|c|c|c|c|c|c|c|c|c|c|c|}
\hline ID & $3 \mathrm{~A} 4$ & $3 A 5$ & 2D6 & $2 \mathrm{C} 8$ & $2 \mathrm{C} 9$ & 2C19 & 2B6 & 1A2 & 2E1 & $2 \mathrm{~A} 6$ & $\begin{array}{c}\text { Negative } \\
\text { Control }\end{array}$ \\
\hline & $n=2$ & $n=2$ & $n=2$ & $n=2$ & $n=2$ & $n=2$ & $n=2$ & $n=2$ & $n=2$ & $n=2$ & $n=2$ \\
\hline MC1 & $(+)$ & $(+)$ & - & - & - & - & - & - & - & - & - \\
\hline $\mathrm{MC} 2 \mathrm{a}-\mathrm{b}$ & + & $(+)$ & - & - & - & - & - & - & - & - & - \\
\hline MC3 & $(+)$ & & - & - & - & - & - & - & - & - & - \\
\hline MC4 & - & - & - & - & - & - & - & - & - & - & - \\
\hline MCArt1 & $(+)$ & $(+)$ & - & - & - & - & - & - & - & - & - \\
\hline MC5 & - & - & - & - & - & - & - & - & - & - & - \\
\hline MC6 & $(+)$ & $(+)$ & - & - & - & - & - & - & - & - & - \\
\hline MC7 & $(+)$ & $(+)$ & - & - & - & - & - & - & - & - & - \\
\hline MC8a-e & + & + & $(+)$ & $(+)$ & $(+)$ & $(+)$ & - & - & - & - & - \\
\hline MC9 & $(+)$ & & & & - & & - & - & - & - & - \\
\hline
\end{tabular}


Table 2. Cont.

\begin{tabular}{|c|c|c|c|c|c|c|c|c|c|c|c|}
\hline ID & 3A4 & 3A5 & $2 \mathrm{D} 6$ & $2 \mathrm{C} 8$ & $2 C 9$ & 2C19 & $2 B 6$ & $1 \mathrm{~A} 2$ & 2E1 & $2 \mathrm{~A} 6$ & $\begin{array}{c}\text { Negative } \\
\text { Control }\end{array}$ \\
\hline & $n=2$ & $n=2$ & $n=2$ & $n=2$ & $n=2$ & $n=2$ & $n=2$ & $n=2$ & $n=2$ & $n=2$ & $n=2$ \\
\hline MCArt2a-b & + & + & $(+)$ & $(+)$ & - & $(+)$ & - & - & - & - & - \\
\hline MC10 & + & + & - & - & - & - & - & - & - & - & - \\
\hline MC11 & + & $(+)$ & - & - & - & - & - & - & - & - & - \\
\hline MC12 & ++ & + & - & - & - & - & - & - & - & - & - \\
\hline MC13 & $(+)$ & - & - & - & - & - & - & - & - & - & - \\
\hline MC14 & + & + & $(+)$ & $(+)$ & - & $(+)$ & - & - & - & - & - \\
\hline MC15 & $(+)$ & - & - & - & - & & - & - & - & - & - \\
\hline MC16 & ++ & ++ & + & $(+)$ & - & $(+)$ & - & - & - & - & - \\
\hline MC17 & + & $(+)$ & - & - & - & - & - & - & - & - & - \\
\hline MC18 & + & $(+)$ & - & - & - & - & - & - & - & - & - \\
\hline MC19a-b & +++ & ++ & ++ & + & $(+)$ & + & $(+)$ & $(+)$ & - & - & - \\
\hline MCArt3 & +++ & +++ & +++ & ++ & + & ++ & + & + & $(+) *$ & $(+)^{*}$ & $(+) *$ \\
\hline MC20 & + & $(+)$ & - & - & - & - & - & - & - & - & - \\
\hline MC21 & +++ & +++ & ++ & ++ & + & ++ & $(+)$ & $(+)$ & - & - & - \\
\hline MCArt4 & +++ & +++ & +++ & +++ & + & +++ & $(+) *$ & $(+) *$ & $(+) *$ & $(+)^{*}$ & $(+) *$ \\
\hline MC22 & ++ & + & $(+)$ & $(+)$ & - & $(+)$ & - & - & - & - & - \\
\hline
\end{tabular}

\subsection{Metabolite Identification for ADAMANTYL-THPINACA}

ADAMANTYL-THPINACA was prone to hydroxylation at the adamantyl-moiety and, to a lesser extent, at the 1-(tetrahydropyranyl-4-methyl)-indazole-3-carboxamidemoiety. Extensive hydroxylation at the adamantyl-moiety has also been observed for other adamantyl-bearing SCRAs [31,46,47]. Overall, one mono-hydroxylated (M12), three di-hydroxylated (MA5, MA7, MA9), and four tri-hydroxylated (MA1, MA2, MA4, MA6) were detected. During analysis, two artefacts were detected (MAArt1 and MAArt2), resulting from in-source water loss of di- and a tri-hydroxylated metabolites. In-source water loss was ruled out for three additional metabolites produced via hydroxylation with concurrent desaturation (MA3, MA8, MA11) and mono-hydroxylation in combination with carbonylation (MA10 and MA13). In this study, a total of 13 metabolites were detected for ADAMANTYL-THPINACA (see Table 3). Kadomura et al. reported nine metabolites resulting from phase I metabolism and two glucuronidated metabolites resulting from phase II metabolism [31]. Regarding the previously reported phase I metabolites produced via mono-, di-, and tri-hydroxylation, the results of our study are in good agreement with theirs, with the exception of one additional tri-hydroxylated metabolite that was not detected in our study. This was most probably due to insufficient chromatographic resolution. However, Kadomura et al. did not present the herein observed metabolites produced from hydroxylation in combination with desaturation (MA3, MA8, MA11) and the two mono-hydroxylated and carbonylated metabolites (MA10 and MA13). In the presented study, MA3 and MA8 were ranked as the third and fourth most abundant metabolites, while the rest could be considered as minor metabolites, and thus more likely of limited importance as biomarkers in the in vivo setting. In contrast to Kadomura et al. we did not study the phase II metabolism.

A chromatogram showing the mass traces of all the above-mentioned metabolites and signals in this study is given in Figure 4. Due to the high abundancy of the dihydroxylated metabolite MA9, this metabolite is suggested as a suitable biomarker for urine screenings. Nevertheless, due to limitations of in vitro models, verification in vivo by 
ana-lysis of positive human urine samples is needed. The proposed metabolic pathway is presented in Figure 5. Fragmentation of the parent compound ADAMANTYL-THPINACA resulted in only one fragment at $m / z$ 135.1168. Variation of the collision energies did not result in more diagnostic ions for the parent compound (data not shown). Additional diagnostic fragments were detected for the metabolites of ADAMANTYL-THPINACA. The respective $\mathrm{MS}^{2}$ spectra of ADAMANTYL-THPINACA, incorporating the three most abundant metabolites with their suggested fragments, are shown in Figure 6.

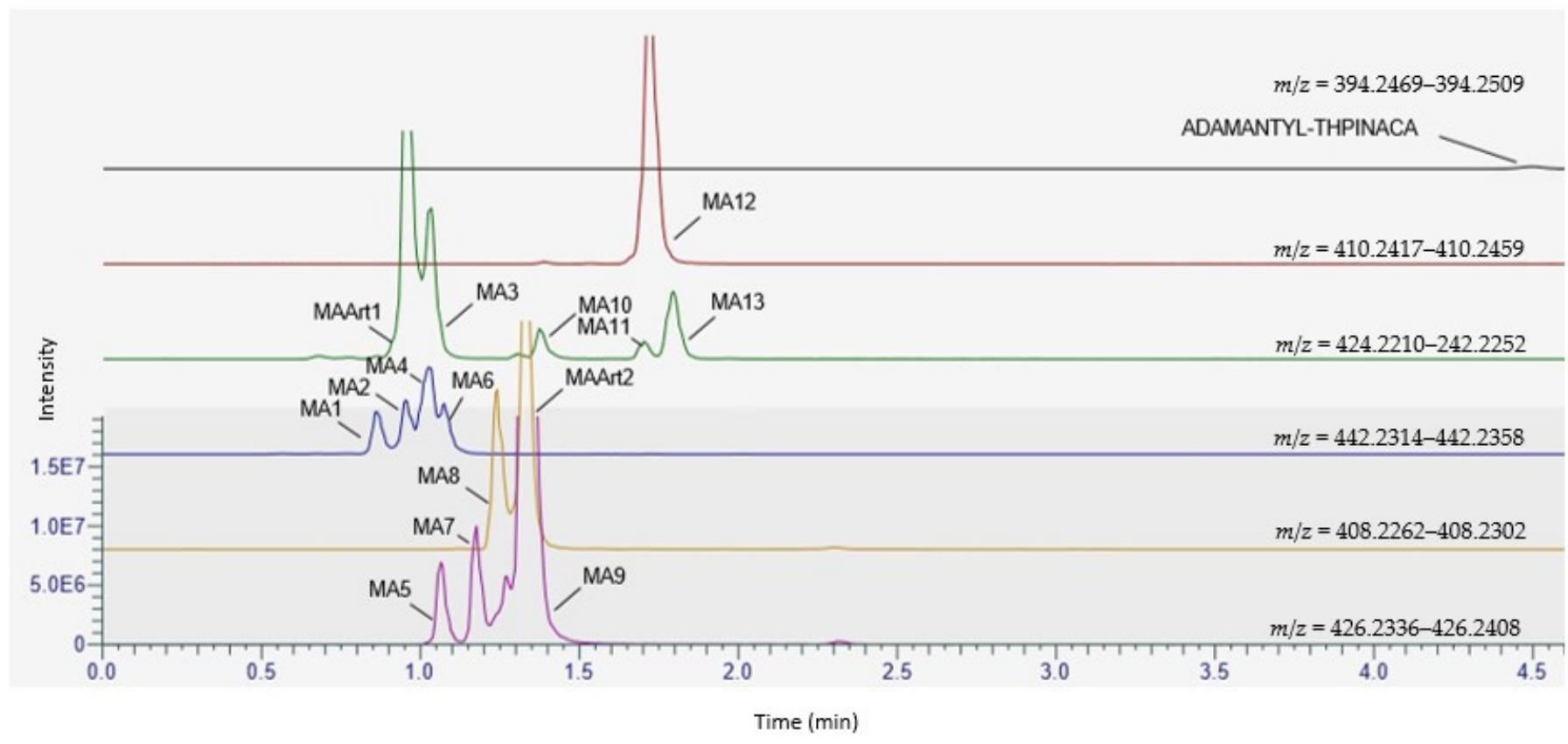

Figure 4. Chromatogram showing the mass traces of the detected metabolites (and artefacts) of ADAMANTYL-THPINACA after $2 \mathrm{~h}$ of incubation. The traces are normalized globally, with a maximum at $12 \%$ of the base peak (MA9). 


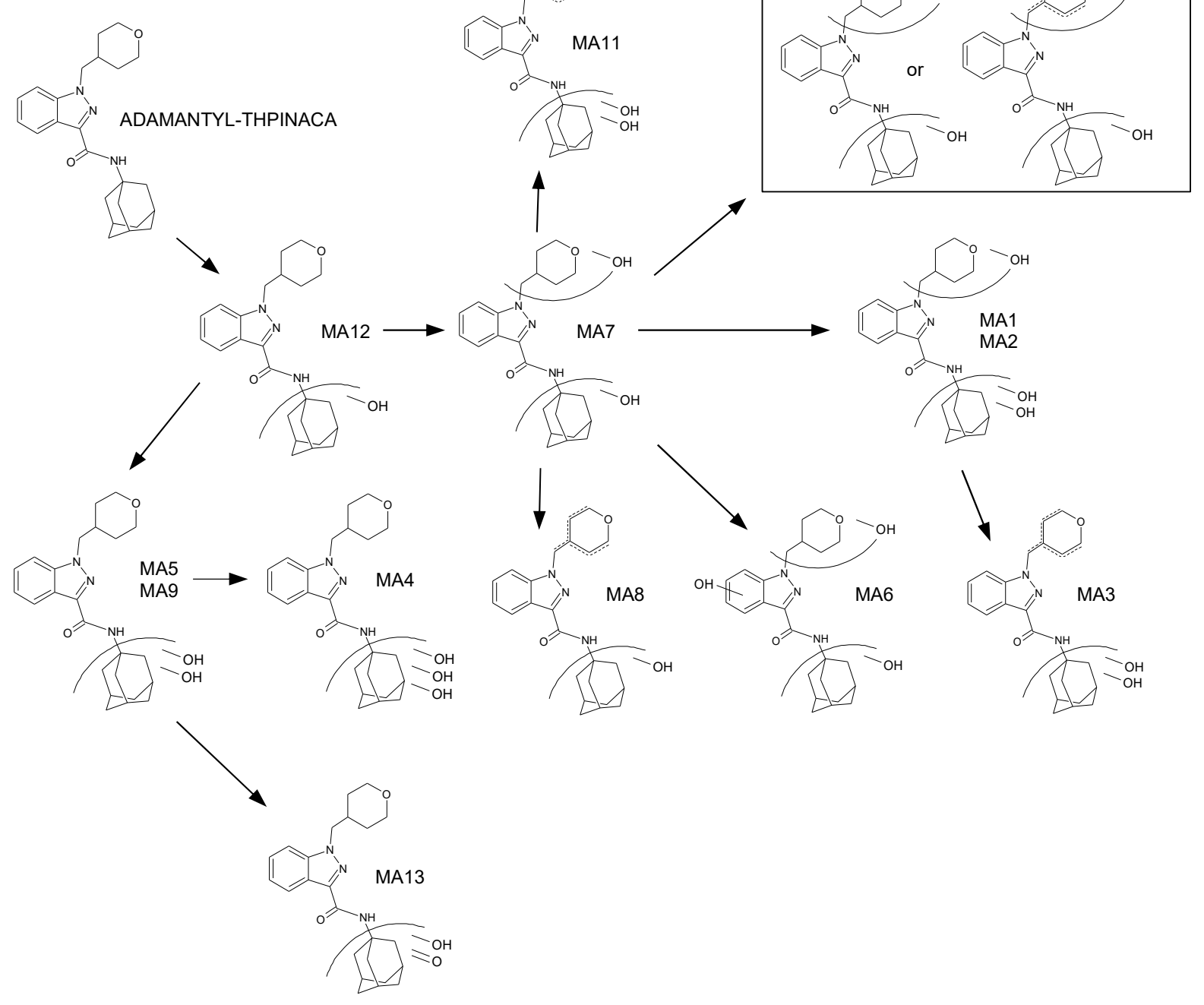

Figure 5. Proposed metabolic pathway of ADAMANTYL-THPINACA. 

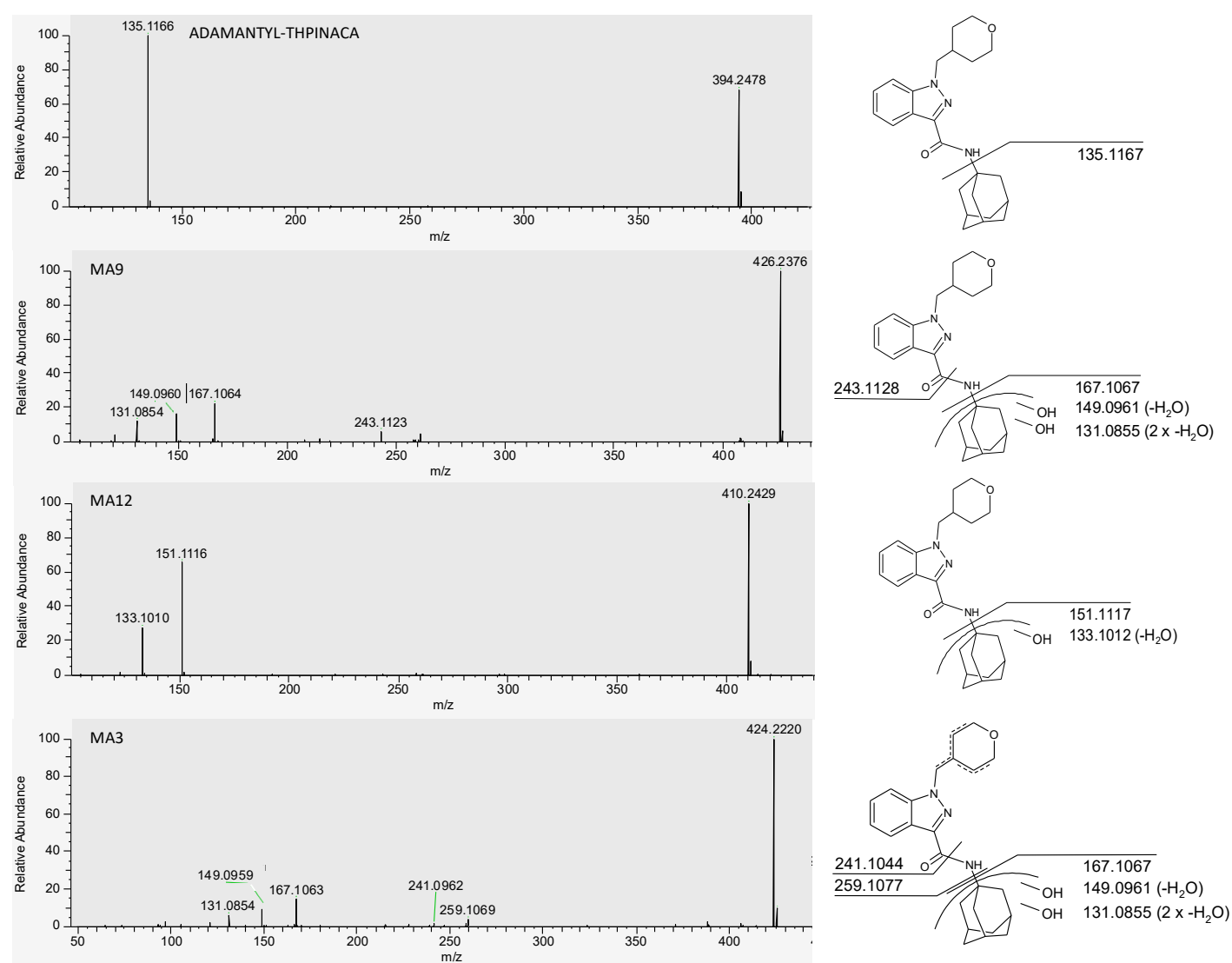

Figure 6. MS2 spectra of ADAMANTYL-THPINACA and its three most abundant metabolites. The proposed fragments leading to the respective signals are shown on the right. 
Table 3. Summary of all detected metabolites, and observed artefacts thereof, of ADAMANTY-THPINACA (listed in the order of the observed retention times). Shown are the suggested biotransformations, chemical formulas, calculated [M + H] of the parent ions and the corresponding product ions, as well as retention times, area after $2 \mathrm{~h}$ of incubation, and rank.

\begin{tabular}{|c|c|c|c|c|c|c|c|}
\hline ID & Biotransformation & Formula & $\begin{array}{l}{[\mathrm{M}+\mathrm{H}]^{+}} \\
\text {Product ions } \\
\quad(\mathrm{m} / z)\end{array}$ & $\begin{array}{l}\text { Mass error } \\
(\mathrm{ppm})\end{array}$ & $\begin{array}{c}\text { Rt } \\
(\mathrm{min})\end{array}$ & $\begin{array}{c}\text { Area } \\
(n=2)\end{array}$ & Rank \\
\hline MA1 & $\begin{array}{c}\text { di-hydroxylation at adamantyl, } \\
\text { mono-hydroxylation at } \\
\text { 4-methyl-tetrahydropyran }\end{array}$ & $\mathrm{C}_{24} \mathrm{H}_{31} \mathrm{~N}_{3} \mathrm{O}_{5}$ & $\begin{array}{l}442.2336 \\
424.2221 \\
259.1077 \\
167.1067 \\
149.0961 \\
131.0855\end{array}$ & 1.4 & 0.87 & $9.2 \times 10^{6}$ & 11 \\
\hline MA2 & $\begin{array}{c}\text { di-hydroxylation at adamantyl, } \\
\text { mono-hydroxylation at } \\
\text { 4-methyl-tetrahydropyran }\end{array}$ & $\mathrm{C}_{24} \mathrm{H}_{31} \mathrm{~N}_{3} \mathrm{O}_{5}$ & $\begin{array}{l}442.2336 \\
424.2221 \\
259.1077 \\
167.1067 \\
149.0961 \\
131.0855\end{array}$ & -0.7 & 0.97 & $1.1 \times 10^{7}$ & 10 \\
\hline MAArt1 & in-source water loss of MA2 & $\mathrm{C}_{24} \mathrm{H}_{29} \mathrm{~N}_{3} \mathrm{O}_{4}$ & $\begin{array}{l}424.2231 \\
259.1077 \\
241.1044 \\
167.1067 \\
149.0961 \\
131.0855\end{array}$ & -0.7 & 0.98 & $7.5 \times 10^{7}$ & \\
\hline MA3 & $\begin{array}{c}\text { di-hydroxylation at adamantyl, } \\
\text { desaturation at } \\
\text { 4-methyl-tetrahydropyran }\end{array}$ & $\mathrm{C}_{24} \mathrm{H}_{29} \mathrm{~N}_{3} \mathrm{O}_{4}$ & $\begin{array}{l}424.2231 \\
259.1077 \\
241.1044 \\
167.1067 \\
149.0961 \\
131.0855\end{array}$ & -0.5 & 1.03 & $3.8 \times 10^{7}$ & 3 \\
\hline MA4 & tri-hydroxylation at adamantyl & $\mathrm{C}_{24} \mathrm{H}_{31} \mathrm{~N}_{3} \mathrm{O}_{5}$ & $\begin{array}{l}442.2336 \\
424.2231 \\
260.1393 \\
243.1128\end{array}$ & -0.5 & & & \\
\hline MA5 & di-hydroxylation at adamantyl & $\mathrm{C}_{24} \mathrm{H}_{31} \mathrm{~N}_{3} \mathrm{O}_{3}$ & $\begin{array}{l}426.2387 \\
260.1394 \\
243.1128 \\
167.1067 \\
149.0961 \\
131.0855 \\
\end{array}$ & 1.2 & 1.09 & $1.7 \times 10^{7}$ & 8 \\
\hline MA6 & $\begin{array}{l}\text { mono-hydroxylation at } \\
\text { adamantyl, } \\
\text { mono-hydroxylation at } \\
\text { indazole, mono-hydroxylation } \\
\text { at 4-methyl-tetrahydropyran }\end{array}$ & $\mathrm{C}_{24} \mathrm{H}_{31} \mathrm{~N}_{3} \mathrm{O}_{5}$ & $\begin{array}{l}442.2336 \\
424.2221 \\
406.2114 \\
151.1117 \\
133.1012 \\
274.1186 \\
257.0921\end{array}$ & 0 & 1.1 & $1.3 \times 10^{7}$ & 9 \\
\hline MA7 & $\begin{array}{c}\text { mono-hydroxylation at } \\
\text { adamantyl, } \\
\text { mono-hydroxylation at } \\
\text { 4-methyl-tetrahydropyran }\end{array}$ & $\mathrm{C}_{24} \mathrm{H}_{31} \mathrm{~N}_{3} \mathrm{O}_{3}$ & $\begin{array}{l}426.2387 \\
151.1117 \\
133.1012\end{array}$ & 0.5 & 1.2 & $2.4 \times 10^{7}$ & 6 \\
\hline MA8 & $\begin{array}{l}\text { Mono-hydroxylation at } \\
\text { adamantyl, desaturation at } \\
\text { 4-methyl-tetrahydropyran }\end{array}$ & $\mathrm{C}_{24} \mathrm{H}_{29} \mathrm{~N}_{3} \mathrm{O}_{3}$ & $\begin{array}{c}408.2282 \\
151.1117 \\
133.10118\end{array}$ & -0.2 & 1.27 & $3.2 \times 10^{7}$ & 4 \\
\hline
\end{tabular}


Table 3. Cont.

\begin{tabular}{|c|c|c|c|c|c|c|c|}
\hline ID & Biotransformation & Formula & $\begin{array}{l}{[\mathrm{M}+\mathrm{H}]^{+}} \\
\text {Product ions } \\
\quad(\mathrm{m} / \mathrm{z})\end{array}$ & $\begin{array}{l}\text { Mass error } \\
\quad(\mathrm{ppm})\end{array}$ & $\begin{array}{c}\mathrm{Rt} \\
(\mathrm{min})\end{array}$ & $\begin{array}{c}\text { Area } \\
(n=2)\end{array}$ & Rank \\
\hline MA9 & di-hydroxylation at adamantyl & $\mathrm{C}_{24} \mathrm{H}_{31} \mathrm{~N}_{3} \mathrm{O}_{3}$ & $\begin{array}{l}426.2387 \\
243.1128 \\
167.1067 \\
149.0961 \\
131.0855\end{array}$ & -1.2 & 1.36 & $4.2 \times 10^{8}$ & 1 \\
\hline MAArt2 & in-source water loss of MA9 & $\mathrm{C}_{24} \mathrm{H}_{29} \mathrm{~N}_{3} \mathrm{O}_{3}$ & $\begin{array}{l}408.2282 \\
260.1394 \\
243.1128 \\
149.0961 \\
131.0855\end{array}$ & -0.7 & 1.36 & $7.9 \times 10^{7}$ & \\
\hline MA10 & $\begin{array}{l}\text { Mono-hydroxylation at } \\
\text { adamantyl, and carbonylation } \\
\text { or mono-hydroxylation and } \\
\text { desaturation at } \\
\text { 4-methyl-tetrahydropyran }\end{array}$ & $\mathrm{C}_{24} \mathrm{H}_{29} \mathrm{~N}_{3} \mathrm{O}_{4}$ & $\begin{array}{l}424.2231 \\
151.1117 \\
133.1012\end{array}$ & 0 & 1.39 & $6.9 \times 10^{6}$ & 12 \\
\hline MA11 & $\begin{array}{c}\text { Di-hydroxylation at adamantyl, } \\
\text { desaturation at } \\
\text { 4-methyl-tetrahydropyran }\end{array}$ & $\mathrm{C}_{24} \mathrm{H}_{29} \mathrm{~N}_{3} \mathrm{O}_{4}$ & $\begin{array}{l}424.2231 \\
259.1077 \\
167.1067 \\
149.0961 \\
131.0855\end{array}$ & -0.9 & 1.73 & $4.1 \times 10^{6}$ & 13 \\
\hline MA12 & $\begin{array}{l}\text { mono-hydroxylation at } \\
\text { adamantyl }\end{array}$ & $\mathrm{C}_{24} \mathrm{H}_{31} \mathrm{~N}_{3} \mathrm{O}_{3}$ & $\begin{array}{l}410.2438 \\
151.1117 \\
133.1012\end{array}$ & -0.5 & 1.75 & $7.6 \times 10^{7}$ & 2 \\
\hline MA1 & $\begin{array}{l}\text { carbonylation and } \\
\text { mono-hydroxylation at } \\
\text { adamantyl }\end{array}$ & $\mathrm{C}_{24} \mathrm{H}_{29} \mathrm{~N}_{3} \mathrm{O}_{4}$ & $\begin{array}{c}424.2231 \\
406.2125 \\
260.1394 \\
243.1128 \\
165.091 \\
119.0855\end{array}$ & 0.2 & 1.8 & $1.8 \times 10^{7}$ & 7 \\
\hline \multicolumn{2}{|c|}{ ADAMANTYL-THPINACA } & $\mathrm{C}_{24} \mathrm{H}_{31} \mathrm{~N}_{3} \mathrm{O}_{3}$ & $\begin{array}{l}394.2489 \\
135.1167\end{array}$ & 0.6 & 4.56 & $1.0 \times 10^{6}$ & - \\
\hline
\end{tabular}

\subsubsection{Mono-Hydroxylation}

MA12 is produced via mono-hydroxylation at the adamantyl-moiety, as shown by the diagnostic fragment at $m / z 151.1117$.

\subsubsection{Di-Hydroxylation}

For MA7, the observed fragment of $m / z 151.1117$ indicated mono-hydroxylation at the adamantyl-moiety. Therefore, the second hydroxyl group is located at the rest of the molecule. Because derivatization did not change the signal intensity of the MA7 metabolites, this suggests that the second hydroxyl-group is located at the 4-methyl-tetrahydropyranmoiety. The di-hydroxylated metabolite MA9 was the most abundant metabolite. Due to the fragment observed at $m / z 167.1067$, the location of both hydroxyl groups was assigned to the adamantyl-moiety. Additional fragments consisted of two dehydration reactions of the di-hydroxylated adamantyl moiety $(\mathrm{m} / z 149.0961$ and $m / z$ 131.0855) and the unaltered 1-(tetrahydropyranyl-4-methyl)-indazole-3-acylium-ion $(m / z$ 243.1128). Two additional, but less abundant, di-hydroxylated metabolites were detected, of which MA5 showed a similar fragmentation pattern to MA9, thus being di-hydroxylated at the adamantylmoiety. As MAArt2, presenting fragments at $m / z 149.0961$ and $m / z 131.0855$ indicating dehydration reactions at the hydroxylated adamantyl-moiety, co-eluted with the metabolite MA9, MAArt2 was classified as an in-source artefact produced by dehydration of MA9. 


\subsubsection{Mono-Hydroxylation and Additional Desaturation}

The metabolite MA8 is produced via mono-hydroxylation at the adamantyl-moiety, indicated by fragment $m / z 151.1117$. The observed desaturation was assigned to the rest of the molecule (4-methyl-tetrahydropyran-moiety), even though the corresponding fragment was not detected due to neutral loss. As MA8 did not co-elute with a di-hydroxylated metabolite, which is mono-hydroxylated at the adamantyl-moiety as well as at the 4-methyltetrahydropyran-moiety, this signal was classified as a genuine metabolite.

\subsubsection{Tri-Hydroxylation}

The two early-eluting metabolites, MA1 and MA2, were identified to be di-hydroxylated at the adamantyl-moiety and mono-hydroxylated at the 1-(tetrahydropyranyl-4-methyl)indazole-3-carboxamide structure. For these two metabolites, the observed fragment at $m / z$ 167.2066 represents the di-hydroxylated adamantyl-moiety and the fragment at $m / z 259.1077$ denotes the mono-hydroxylated 1-(tetrahydropyranyl-4-methyl)-indazole3-acylium-ion. As derivatization did not result in methylation of MA1 and MA2, it was concluded that both metabolites are produced via hydroxylation at the 4-methyltetrahydropyran-moiety. MAArt1 was detected via the parent ion at $m / z 424.2231$ and is denoted as an in-source dehydration artefact. MAArt1 was identified to be di-hydroxylated at the adamantyl-moiety $(\mathrm{m} / \mathrm{z}$ 167.1067) and desaturated at the 4-methyl-tetrahydropyranmoiety $(m / z$ 259.1077). Due to the presence of the coeluting tri-hydroxylated metabolite MA2, showing the same alterations, a potential contribution from MAArt1 to the observed MA2 signal could not be ruled out. MA4 presented MS ${ }^{2}$ spectra with two fragments at $m / z$ 260.1393 and $m / z 243.1128$, both indicating an unaltered 1-(tetrahydropyranyl-4-methyl)indazole-3-carboxamide moiety. It was consequently concluded that the adamantyl-moiety was hydroxylated three times, despite the fragment representing this moiety not being detected, due to neutral loss. The latest eluting tri-hydroxylated metabolite MA6 is produced via mono-hydroxylation at the adamantyl-moiety, shown by the diagnostic fragment at $m / z 151.1117$, and di-hydroxylation of the remaining molecule. One observed fragment of MA6 at $m / z 274.1184$ is produced via dehydration of the 1-(tetrahydropyranyl-4-methyl)indazole-3-carboxamide-moiety. Therefore, one hydroxyl group must be located at the 4-methyl-tetrahydropyran-moiety. As no second dehydration reaction of this moiety was detected, the third hydroxy group was proposed to be located at the indazole-core. The location of the hydroxyl group at the indazole-moiety was verified via derivatization, as the corresponding methylated metabolite MA6 was detected at $m / z$ 456.2493. Additionally, fragmentation of this product resulted in a fragment with $m / z 288.1343$, indicative of the methylated and desaturated 1-(tetrahydropyranyl-4-methyl)-indazole-3-carboxamidemoiety.

\subsubsection{Di-Hydroxylation and Additional Desaturation, Mono-Hydroxylation and Additional Carbonylation}

Fragmentation of MA3 with $[\mathrm{M}+\mathrm{H}]^{+} 424.2231(\mathrm{~m} / z)$, resulted in a fragment at $\mathrm{m} / \mathrm{z}$ 167.1067, indicating di-hydroxylation at the adamantyl-moiety. Additionally, the desaturated 4-methyl-tetrahydropyran-moiety was identified with the detected $m / z 259.1077$, a fragment indicative of the desaturated 1-(tetrahydropyranyl-4-methyl)-indazole-3-carboxylicacid-moiety after amide hydrolysis. Due to the lack of a tri-hydroxylated counterpart, in-source dehydration was not considered for MA3. The metabolite MA10 resulted in a fragment at $m / z$ 151.1117, representing the mono-hydroxylated adamantyl-moiety. A fragment produced from subsequent water loss at the adamantyl-moiety was also detected at $m / z$ 133.1012. Due to a lack of further fragments, as a result of neutral loss, it was concluded that further sites of biotransformation are located elsewhere on the molecule. Potential biotransformations resulting in the signal at $m / z 424.2231$ include di-hydroxylation and desaturation (likely derived from dehydration of a tri-hydroxylated metabolite, which was not detected) or mono-hydroxylation in combination with carbonylation. As derivatization did not result in a decrease of the MA10-signal, hydroxylation at the indazole-region 
was ruled out. In conclusion, MA10 was defined as the product of mono-hydroxylation at the adamantyl-region with concurrent mono-hydroxylation and desaturation or carbonylation at the 4-methyl-tetrahydropyran-moiety. Due to the later elution of MA10, when compared to the detected tri-hydroxylated metabolites, in-source dehydration was not considered. MA11 is a further metabolite with a parent ion at $m / z 424.2231$, in this case as a result of di-hydroxylation and desaturation, as indicated by the detection of the di-hydroxylated adamantyl-moiety at $m / z$ 167.1067. As this fragment was observed, the location of desaturation was concluded to be at the 4-methyl-tetrahydropyran-moiety. As no corresponding tri-hydroxylated metabolites were detected within the MA11 elution window, in-source dehydration of this metabolite is unlikely. MA13 is classified as a product of mono-hydroxylation and carbonylation. This was concluded from the presence of $m / z 260.1393$ (unaltered 1-(tetrahydropyranyl-4-methyl)-indazole-3-carboxamide structure) and $m / z 165.0910$ (mono-hydroxylation and carbonylation of the adamantylmoiety). An additional fragment $(m / z$ 119.0855) was detected, assigned to the cleavage of $\mathrm{CO}$ and dehydration of the mono-hydroxylated and carbonylated adamantyl-moiety. The longer retention time of this metabolite when compared to hydroxylated and desaturated metabolites is also in accordance with carbonylation, due to the expected lower polarity of a carbonyl group in comparison to a hydroxyl group.

\subsubsection{Identification of the Primarily Involved CYP Isoenzymes}

As for CUMYL-THPINACA, CYP3A4 and CYP3A5 were found to mainly contribute to the metabolism of ADAMANTYL-THPINACA (Table 4). In contrast to CUMYLTHPINACA, limited metabolic activity of CYP2D6, and CYP2C8 was observed. CYP2C9 and CYP2C19 mediated the production of M12, but no other metabolites, thus leading to the conclusion that these isoforms play a minor role in the metabolism of ADAMANTYLTHPINACA. For CYP2B6, CYP1A2, CYP2E1 und CYP2A6, no metabolic activity could be observed.

Experiments revealed CYP3A4 also to be the major metabolizing CYP for ADAMANTYLTHPINACA. In comparison to CUMYL-THPINACA, far fewer CYP isoforms were involved in ADAMANTYL-THPINACA metabolism. The intake of strong CYP3A4 inhibitors together with ADAMANTYL-THPINACA is more likely to pose a higher risk of metabolic drug-drug interactions than CYP3A4 in combination with CUMYL-THPINACA.

Table 4. Summary of the incubation results of ADAMANTYL-THPINACA with rCYP. Area ratios (absolute peak are (metabolite)/absolute peak area (ISTD)) are expressed as follows: $(+):<0.1,+: \geq 0.1-\leq 1,++:>1-\leq 5,+++:>5$. Where the negative control contained trace amounts of metabolites in a comparable amount, as in the samples after incubation, the result is marked as: $(+)^{*}$.

\begin{tabular}{|c|c|c|c|c|c|c|c|c|c|c|c|}
\hline ID & $3 \mathrm{~A} 4$ & $3 A 5$ & 2D6 & $2 \mathrm{C} 8$ & $2 \mathrm{C} 9$ & $2 C 19$ & $2 B 6$ & $1 \mathrm{~A} 2$ & 2E1 & $2 \mathrm{~A} 6$ & $\begin{array}{c}\text { Negative } \\
\text { Control }\end{array}$ \\
\hline & $n=2$ & $n=2$ & $n=2$ & $n=2$ & $n=2$ & $n=2$ & $n=2$ & $n=2$ & $n=2$ & $n=2$ & $n=2$ \\
\hline MA1 & + & $(+)$ & - & - & - & - & - & - & - & - & - \\
\hline MA2 & + & $(+)$ & - & - & - & - & - & - & - & - & - \\
\hline MAArt1 & ++ & $(+)$ & - & - & - & - & - & - & - & - & - \\
\hline MA3 & ++ & $(+)$ & - & - & - & - & - & - & - & - & - \\
\hline MA4 & + & $(+)$ & - & - & - & - & - & - & - & - & - \\
\hline MA5 & + & $(+)$ & $(+)$ & $(+)$ & - & - & - & - & - & - & - \\
\hline MA6 & $(+)$ & $(+)$ & - & - & - & - & - & - & - & - & - \\
\hline MA7 & + & $(+)$ & $(+)$ & $(+)$ & - & - & - & - & - & - & - \\
\hline MA8 & + & ++ & + & $(+)$ & - & - & - & - & - & - & - \\
\hline MA9 & +++ & ++ & $(+)$ & $(+)$ & - & - & - & - & - & - & - \\
\hline
\end{tabular}


Table 4. Cont.

\begin{tabular}{cccccccccccc}
\hline \multirow{2}{*}{ ID } & $3 \mathrm{~A} 4$ & $3 \mathrm{AA} 5$ & $2 \mathrm{D} 6$ & $2 \mathrm{C} 8$ & $2 \mathrm{C} 9$ & $2 \mathrm{C} 19$ & $2 \mathrm{~B} 6$ & 1A2 & 2E1 & 2A6 & $\begin{array}{c}\text { Negative } \\
\text { Control }\end{array}$ \\
\cline { 2 - 10 } & $n=2$ & $n=2$ & $n=2$ & $n=2$ & $n=2$ & $n=2$ & $n=2$ & $n=2$ & $n=2$ & $n=2$ & $n=2$ \\
\hline MAArt2 & ++ & + & $(+)$ & $(+)$ & - & - & - & - & - & - & - \\
\hline MA10 & $(+)$ & $(+)$ & - & - & - & - & - & - & - & - & - \\
\hline MA11 & $(+)$ & $(+)$ & - & - & - & - & - & - & - & - & - \\
\hline MA12 & + & +++ & ++ & +++ & + & + & $(+)^{*}$ & $(+)^{*}$ & $(+)^{*}$ & $(+)^{*}$ & $(+)^{*}$ \\
\hline MA13 & + & $(+)$ & - & - & - & - & - & - & - & - & - \\
\hline
\end{tabular}

3. Materials and Methods

\subsection{Chemicals and Reagents}

LC-MS grade acetonitrile (ACN), methanol $(\mathrm{MeOH})$, and water, and HPLC grade acetone and 2-isopropanol (IPA) were obtained from Macherey-Nagel AG (Oensingen, Switzerland). Ammonium formate ( $>99.0 \%$ ), ethyl acetate (EtOAc, HPLC grade), iodomethane (stabilized with silver), and formic acid (98-100\%) were purchased from Merck (Zug, Switzerland). Potassium carbonate (Ph. Eur.) was purchased from Carl Roth AG (Arlesheim, Switzerland). Certified reference standards of UR-144, UR-144 N-(5-hydroxypentyl) metabolite, UR-144 N-pentanoic acid metabolite, and d,1-11-Hydroxy-THC-D 3 were purchased from Lipomed AG (Arlesheim, Switzerland). CUMYL-THPINACA (N-(1-methyl-1-phenylethyl)-1(tetrahydropyran-4-ylmethyl)-1H-indazole-3-carboxamide; purity $>97 \%$ ) and ADAMANTYLTHPINACA (N-(1-adamantyl)1-(tetrahydropyran-4-ylmethyl)-1H-indazole-3-carboxamide; purity $>93 \%$ ) were kindly provided by the Zurich Forensic Science Institute (Switzerland) in solid form (as certified reference substances were not available at the time of this work). Stock solutions were prepared at $1 \mathrm{mg} / \mathrm{mL}$ in $\mathrm{MeOH}$ for both compounds and stored at $-20^{\circ} \mathrm{C}$ until use. Pooled human liver microsomes (donor pool $>20,20$ $\mathrm{mg} / \mathrm{mL}$ protein content in $250 \mathrm{mM}$ sucrose, specified total P450 enzyme content of 360 $\mathrm{pmol} / \mathrm{mg}$ protein) and Gentest NADPH regenerating system solutions: A (containing $26 \mathrm{mM} \beta$-nicotinamide adenine dinucleotide phosphate [NADP ${ }^{+}$], 66m MD-glucose-6phosphate [Glc-6-P], $66 \mathrm{mMmagnesium}$ chloride $\left[\mathrm{MgCl}_{2}\right]$ in water), and $\mathrm{B}$ (containing 40 $\mathrm{U} / \mathrm{mL}$ Glc-6-P dehydrogenase [Glc-6-P-DH; EC 1.1.1.49] in sodium citrate) were purchased from Corning (Amsterdam, The Netherlands). Human CYP3A4 (100 pmol/mg protein), CYP2C9 (100 $\mathrm{pmol} / \mathrm{mg}$ protein), CYP2E1 (100 $\mathrm{pmol} / \mathrm{mg}$ protein), CYP3A5 (100 $\mathrm{pmol} / \mathrm{mg}$ protein), CYP2C8 (100 pmol/mg protein), CYP2B6 (100 pmol/mg protein), CYP2A6 (with purified human cytochrome $\mathrm{b} 5,100 \mathrm{pmol} / \mathrm{mg}$ protein), CYP1A2 (770 $\mathrm{pmol} / \mathrm{mg}$ protein), CYP2D6 (142 $\mathrm{pmol} / \mathrm{mg}$ protein), CYP2C19 (202 pmol/mg protein), CYP3A5, and CYP2B6 EasyCYP Bactosomes co-expressed with human CYP-reductase in Escherichia coli, and membrane protein isolated from Escherichia coli host strain (EasyCYP control, $10 \mathrm{mg} / \mathrm{mL}$ protein), were ordered from tebu-bio (Offenbach, Germany).

\subsection{Microsomal Incubation with $p H L M$}

CUMYL-THPINACA, ADAMANTYL-THPINACA were incubated in duplicate at final concentrations of $10 \mu \mathrm{M}$ in a total reaction volume of $1000 \mu \mathrm{L}$. Following the vendors instructions (Corning), the incubation mixture consisted of $100 \mathrm{mM}$ potassium phosphate buffer (pH 7), $50 \mu \mathrm{L}$ NADPH Regenerating System Solution A, and $10 \mu \mathrm{L}$ NADPH Regenerating System Solution B. The percentage of organic solvent $(\mathrm{MeOH})$ was limited to $0.4 \%$ in the incubation mixture, thus no inhibition due to organic solvents was to be expected (limit for $\mathrm{MeOH}$ defined by Corning: $1 \%$ ). The reaction was started by the addition of 0.5 mg liver microsomes per assay to the reaction mixture that was then tempered to $37^{\circ} \mathrm{C}$. Negative controls were prepared by replacing the pHLMs with an equivalent volume of water and by incubating enzymes without the addition of SCRAs, while parallel incubation of the SCRA UR-144 served as a positive control for the functionality of the incubation. The 
samples were then incubated at $37^{\circ} \mathrm{C}$ in an Eppendorf ThermoStat $\mathrm{C}$ heating block. In a preliminary experiment (data not shown) samples were drawn after $0.5 \mathrm{~h}, 1 \mathrm{~h}, 1.5 \mathrm{~h}$ and 2 $\mathrm{h}$ after incubation with pHLM. For the presented data, the samples were incubated for $2 \mathrm{~h}$, as this incubation time gave the best outcome with respect to number and concentration of metabolites. The reaction was terminated by the addition of an equal volume of ice-cold $\mathrm{ACN}$ to $400 \mu \mathrm{L}$ of drawn sample. The samples were then centrifuged at room temperature for five minutes at 13,400 rpm (approximately $9000 \times g$ ) using an Eppendorf MiniSpin centrifuge (Eppendorf, Schönenbuch, Switzerland). The supernatant was stored in glass vials at $-20^{\circ} \mathrm{C}$ until sample cleanup.

\subsection{Microsomal Incubation with $r C Y P$}

Substrate solutions (final concentration $10 \mu \mathrm{M}$ ) were incubated in $100 \mathrm{mM}$ potassium phosphate buffer ( $\mathrm{pH} 7$ ), containing a final reaction volume of $500 \mu \mathrm{L}$, containing $38 \mu \mathrm{L}$ NADPH regenerating solution A and $13 \mu \mathrm{L}$ NADPH Regenerating Solution B. The reaction was started by the addition $25 \mu \mathrm{L}$ of the CYP-solutions (or negative control EasyCYP), resulting in $0.5 \mathrm{mg}$ protein per assay. Following the vendors instructions (tebu-bio), the reaction was quenched-after incubating for $20 \mathrm{~min}$ at $37^{\circ} \mathrm{C}$ - by addition of $400 \mu \mathrm{L}$ icecold $\mathrm{ACN}$ to $400 \mu \mathrm{L}$ of drawn sample. Subsequently, the samples were centrifuged at $13,400 \mathrm{rpm}$ (approximately $9000 \times g$ ) for five minutes. The supernatant was stored in glass vials at $-20^{\circ} \mathrm{C}$ until further processing.

\subsection{Sample Preparation}

For sample clean-up, a protocol was adapted from one developed for the analysis of metabolites of SCRAs in urine, published by Gaunitz et al. [35]. In brief, $600 \mu \mathrm{L}$ of the supernatants of the precipitated samples were diluted 1:1 with $100 \mathrm{mM}$ ammonium formate buffer ( $\mathrm{pH} 4$ ). At this point the internal standard (ISTD) d,1-11-Hydroxy-THC-D 3 was added, resulting in a concentration of $100 \mathrm{ng} / \mathrm{mL}$ (final concentration at time of analysis, with presumed $100 \%$ recovery, $300 \mathrm{ng} / \mathrm{mL}$ ). Strata phenyl SPE cartridges obtained from Phenomenex (Basel, Switzerland) were conditioned with $2 \mathrm{~mL} \mathrm{MeOH}, 2 \mathrm{~mL}$ water, and $2 \mathrm{~mL}$ ammonium formate buffer $(\mathrm{pH} 4)$, prior to being loaded with the diluted samples. After loading the samples, the cartridges were washed with $2 \mathrm{~mL}$ of 5:95 MeOH:water $(v / v)$ and dried for $15 \mathrm{~min}$. Elution of the analytes was achieved with twice $2 \mathrm{~mL}$ of 85:15 EtOAc:IPA $(v / v)$. Extracts were collected in glass tubes and the solvent was evaporated until dryness at $40{ }^{\circ} \mathrm{C}$ under a gentle stream of nitrogen. Finally, the dried residues were resolved in $200 \mu \mathrm{L}$ of 1:1 ACN:water $(v / v)$, centrifuged $(2465 \times g, 15 \mathrm{~min})$ and transferred to HPLC-vials, thus resulting in a concentration by a factor of 3 .

\subsection{Derivatization Using Iodomethane}

SPE extracts obtained from pHLM incubation experiments were solved in $200 \mu \mathrm{L}$ acetone and then transferred into glass-vials, which were prefilled with a spatula tip (approximately $500 \mathrm{mg}$ ) of potassium carbonate. At this point $100 \mu \mathrm{L}$ iodomethane was added, the vials were closed, and the mixtures were incubated for $1 \mathrm{~h}$ at $60{ }^{\circ} \mathrm{C}$. The samples were transferred into a new vial using a glass Pasteur pipet omitting the insoluble potassium carbonate. The samples were evaporated to dryness under a gentle nitrogen stream at $60^{\circ} \mathrm{C}$, and reconstituted in $200 \mu \mathrm{L}$ 1:1 ACN:water. A negative control was conducted for both SCRAs, where the addition of iodomethane was omitted while the rest of the experiment was kept as above.

\subsection{Analysis}

Chromatographic separation of the metabolites was achieved using a Dionex UltiMate 3000 ultra UHPLC system equipped with a Hypersil Gold $(50 \times 2.1 \mathrm{~mm} 1.9 \mu \mathrm{M})$ analytical column, thermostatted at $40^{\circ} \mathrm{C}$ using a MutliSLEEVE column heater, all obtained from Thermo Fisher Scientific (Reinach, Switzerland). Mobile phase A consisted of water with $0.1 \%(v / v)$ formic acid and mobile phase B of ACN with $0.1 \%(v / v)$ formic acid. After 
injection of $5 \mu \mathrm{L}$ of the prepared sample the gradient commenced at $20 \%$ mobile phase B, which then increased to $40 \%$ within $0.9 \mathrm{~min}$ and to $71 \%$ within the following $6 \mathrm{~min}$, after which the mobile phase B was increased to $100 \%$ during a time interval of $0.25 \mathrm{~min}$ and held for $1 \mathrm{~min}$. The system was then returned to the initial settings and held for 1.25 min, prior to the injection of the next sample. The mobile phase flow was $0.6 \mathrm{~mL} / \mathrm{min}$ throughout. The mobile phase flow during the first $0.1 \mathrm{~min}$ and after $7 \mathrm{~min}$ was directed to the waste and not to the mass spectrometer by means of a bypass valve connected after the column.

Subsequent analysis was undertaken with a Thermo Scientific Q Exactive HF Hybrid Quadrupole-Orbitrap mass spectrometer equipped with a heated electrospray ionization (HESI-II) source, obtained from Thermo Fisher Scientific (Reinach, Switzerland), operated with a sheath gas flow rate of 50 arbitrary units (AU) and an auxiliary gas flow rate of $5 \mathrm{AU}$. The capillary temperature and auxiliary gas heater temperature were $200{ }^{\circ} \mathrm{C}$ and $350{ }^{\circ} \mathrm{C}$, respectively, and the spray voltage was set to $3.5 \mathrm{kV}$. Parent ions of metabolites were screened using a full MS acquisition in positive ion mode and at a resolution of 120,000 full width at half-maximum (FWHM) at $m / z 200$, within a scan range from $m / z 150$ to $\mathrm{m} / z$ 1000. Metabolite identification was conducted by manual investigation of the raw data in FreeStyle (version 1.7, SP1, Thermo Fisher Scientific, Reinach, Switzerland), assisted by the Compound Discoverer (version 3.1, Thermo Fisher Scientific, Reinach, Switzerland) software, by running an expected workflow (Forensics Expected w FiSh scoring), that enables the screening for software predicted products generated by biotransformation of a predefined compound. The software thus calculates the expected masses of common phase I metabolites and searches for corresponding signals in the data. The program additionally identifies background signals by comparison of blank samples and negative control samples, which are then filtered out and, therefore, not considered.

In a subsequent analysis, the software-proposed metabolites were transferred into an inclusion list for a full MS-data-dependent $\mathrm{MS}^{2}\left(\mathrm{dd}-\mathrm{MS}^{2}\right)$ analysis. The resolution for this measurement was set to 60,000 FWHM for the full MS analysis and 15,000 FWHM for the dd-MS ${ }^{2}$ analysis. Normalized stepped collision energies of 10, 17.5, and 35 (normalized to $m / z 500[z=1]$ ) were applied. In order to ensure fragmentation of low abundance and close eluting isobaric compounds, the minimum automated33 gain control (AGC) target to trigger an $\mathrm{MS}^{2}$ measurement was set to zero and dynamic exclusion was set to one second. The generated $\mathrm{MS}^{2}$ spectra were investigated with the aid of Compound Discoverer, which enables comparison of the obtained $\mathrm{MS}^{2}$ spectra to the theoretical in silico generated $\mathrm{MS}^{2}$-spectra [38].

The criterion for metabolite identification was a mass accuracy $<5 \mathrm{ppm}$ for the proposed parent ions and diagnostic fragments along with the plausibility of observed fragments and observed retention times of metabolites in relation to each other. The biotransformations were identified by mass shifts of the detected fragments, indicative of hydroxylation (+15.9994 Da per hydroxylation), desaturation (-2.01565 Da), carbonylation $(+13.9838 \mathrm{Da})$, dehydration $(-18.0153 \mathrm{Da})$, and combinations thereof. The position of hydroxylation was narrowed down by a derivatization experiment employing iodomethane, which selectively methylates aromatic hydroxyl-groups (i.e., cumyl- and indazole-moiety).

\section{Conclusions}

Incubation with pHLM yielded 28 metabolites for CUMYL-THPINACA and 13 metabolites for ADAMANTYL-THPINACA. The observed extensive metabolism of the studied SCRAs again highlight, as previously observed for many other SCRAs, the need to include the metabolites in screening procedures-particularly in urine. Both compounds presented a highly abundant di-hydroxylated metabolite, which is recommended as a suitable target for screening procedures. For both compounds, in-source dehydration artefact formation was observed for a few hydroxylated metabolites, supporting the need for in vitro studies prior to moving on to in vivo measurements. However, several metabolites, sharing the same mass as the described dehydration artefacts, were identified. This 
emphasizes the requirement to thoroughly investigate all signals of potential metabolites in order not to miss potential biomarkers. Furthermore, as some dehydration products presented higher abundancies than the underlying metabolite, their detection may improve investigations of substance use and they should, therefore, be included into screening protocols. However, such recommendations would need to be verified by means of analysis of human urine samples.

The reported protocols, along with the instrumentation and software used, proved to be beneficial for the investigation of SCRA metabolite profiles. The in silico tools were invaluable in speeding up the elucidation of the metabolic profile of the studied SCRAs. Concerning the metabolism, the involvement of mainly CYP3A4 along with CYP3A5, was observed for both compounds. For CUMYL-THPINACA the additional involvement of 2D6, 2C8, and 2C19 was found (all to a lesser extent than for CYP3A4), making CUMYLTHPINACA less susceptible for metabolism-based drug-drug interactions or the effects of CYP-polymorphism. Due to the main involvement of CYP3A4 in the metabolism of ADAMANTYL-THPINACA, metabolic drug-drug interactions in combination with a strong CYP3A4 inhibitor are considered more likely with ADAMANTYL-THPINACA than with CUMYL-THPINACA.

Author Contributions: M.C.M.: data curation, formal analysis, visualization, writing-original draft preparation; M.C.M., K.M.-C.-B., E.S.: conceptualization; M.C.M., K.M.-C.-B.: methodology, investigation; K.M.-C.-B. and E.S.: writing—review and editing; K.M.-C.-B. and E.S.: supervision. All authors have read and agreed to the published version of the manuscript.

Funding: This research received no external funding.

Institutional Review Board Statement: Not applicable.

Informed Consent Statement: Not applicable.

Data Availability Statement: Data is available in the article.

Acknowledgments: The authors thank June Mercer-Chalmers-Bender for English language editing. Special thanks go to Christian Bissig from the Zurich Forensic Science Institute for providing reference material. Further thanks go to Priska Frei for valuable discussions and input during manuscript preparation.

Conflicts of Interest: The authors declare no conflict of interest.

\section{References}

1. European Monitoring Centre for Drugs and Drug Addiction. European Drug Report 2020: Trends and Developments; Publications Office of the EU: Luxembourg, 2020.

2. Castaneto, M.S.; Gorelick, D.A.; Desrosiers, N.A.; Hartman, R.L.; Pirard, S.; Huestis, M.A. Synthetic cannabinoids: Epidemiology, pharmacodynamics, and clinical implications. Drug Alcohol Depend. 2014, 144, 12-41. [CrossRef] [PubMed]

3. Wiley, J.L.; Marusich, J.A.; Huffman, J.W. Moving around the molecule: Relationship between chemical structure and in vivo activity of synthetic cannabinoids. Life Sci. 2014, 97, 55-63. [CrossRef] [PubMed]

4. Gatch, M.B.; Forster, M. Cannabinoid-like effects of five novel carboxamide synthetic cannabinoids. NeuroToxicology 2019, 70, 72-79. [CrossRef] [PubMed]

5. Fantegrossi, W.E.; Moran, J.H.; Radominska-Pandya, A.; Prather, P.L. Distinct pharmacology and metabolism of K2 synthetic cannabinoids compared to $\Delta$ (9)-THC: Mechanism underlying greater toxicity? Life Sci. 2014, 97, 45-54. [CrossRef]

6. Hutchison, R.D.; Ford, B.M.; Franks, L.N.; Wilson, C.D.; Yarbrough, A.L.; Fujiwara, R.; Su, M.K.; Fernandez, D.; James, L.P.; Moran, J.H.; et al. Atypical Pharmacodynamic Properties and Metabolic Profile of the Abused Synthetic Cannabinoid AB-PINACA: Potential Contribution to Pronounced Adverse Effects Relative to $\Delta(9)$-THC. Front. Pharmacol. 2018, 9, 1084. [CrossRef] [PubMed]

7. Angerer, V.; Jacobi, S.; Franz, F.; Auwärter, V.; Pietsch, J. Three fatalities associated with the synthetic cannabinoids 5F-ADB, 5F-PB-22, and AB-CHMINACA. Forensic Sci. Int. 2017, 281, e9-e15. [CrossRef] [PubMed]

8. Harris, C.R.; Brown, A. Synthetic Cannabinoid Intoxication: A Case Series and Review. J. Emerg. Med. 2013, 44, 360-366. [CrossRef]

9. Westin, A.A.; Frost, J.; Brede, W.R.; Gundersen, P.O.; Einvik, S.; Aarset, H.; Slørdal, L. Sudden Cardiac Death Following Use of the Synthetic Cannabinoid MDMB-CHMICA. J. Anal. Toxicol. 2016, 40, 86-87. [CrossRef]

10. Hermanns-Clausen, M.; Kneisel, S.; Szabo, B.; Auwärter, V. Acute toxicity due to the confirmed consumption of synthetic cannabinoids: Clinical and laboratory findings. Addiction 2013, 108, 534-544. [CrossRef] 
11. Trecki, J.; Gerona, R.R.; Schwartz, M.D. Synthetic Cannabinoid-Related Illnesses and Deaths. N. Engl. J. Med. 2015, 373, 103-107. [CrossRef]

12. Kleis, J.; Germerott, T.; Halter, S.; Héroux, V.; Roehrich, J.; Schwarz, C.S.; Hess, C. The synthetic cannabinoid 5F-MDMB-PICA: A case series. Forensic Sci. Int. 2020, 314, 110410. [CrossRef]

13. Norman, C.; Walker, G.; McKirdy, B.; McDonald, C.; Fletcher, D.; Antonides, L.H.; Sutcliffe, O.B.; Nic Daéid, N.; McKenzie, C. Detection and quantitation of synthetic cannabinoid receptor agonists in infused papers from prisons in a constantly evolving illicit market. Drug Test. Anal. 2020, 12, 538-554. [CrossRef]

14. Mogler, L.; Franz, F.; Rentsch, D.; Angerer, V.; Weinfurtner, G.; Longworth, M.; Banister, S.D.; Kassiou, M.; Moosmann, B.; Auwärter, V. Detection of the recently emerged synthetic cannabinoid 5F-MDMB-PICA in 'legal high' products and human urine samples. Drug Test. Anal. 2018, 10, 196-205. [CrossRef] [PubMed]

15. Norman, C.; Halter, S.; Haschimi, B.; Acreman, D.; Smith, J.; Krotulski, A.J.; Mohr, A.L.A.; Logan, B.K.; NicDaéid, N.; Auwärter, $\mathrm{V}$; ; et al. A transnational perspective on the evolution of the synthetic cannabinoid receptor agonists market: Comparing prison and general populations. Drug Test. Anal. 2021, 13, 841-852. [CrossRef] [PubMed]

16. European Monitoring Centre for Drugs and Drug Addiction. EMCDDA Initial Report on the New Psychoactive Substance Methyl 3,3-Dimethyl-2-(1-(Pent-4-En-1-yl)-1H-Indazole-3-Carboxamido)Butanoate (MDMB-4en-PINACA), Initial Reports; Publications Office of the European Union: Luxembourg, 2020. Available online: https://www.emcdda.europa.eu/publications/initial-reports/ mdmb-4en-pinaca_en (accessed on 1 December 2020).

17. Scheidweiler, K.B.; Jarvis, M.J.Y.; Huestis, M.A. Nontargeted SWATH acquisition for identifying 47 synthetic cannabinoid metabolites in human urine by liquid chromatography-high-resolution tandem mass spectrometry. Anal. Bioanal. Chem. 2015, 407, 883-897. [CrossRef]

18. Diao, X.; Huestis, M.A. Approaches, Challenges, and Advances in Metabolism of New Synthetic Cannabinoids and Identification of Optimal Urinary Marker Metabolites. Clin. Pharmacol. Ther. 2017, 101, 239-253. [CrossRef]

19. Franz, F.; Angerer, V.; Moosmann, B.; Auwärter, V. Phase I metabolism of the highly potent synthetic cannabinoid MDMBCHMICA and detection in human urine samples. Drug Test. Anal. 2017, 9, 744-753. [CrossRef]

20. Diao, X.; Huestis, M.A. New Synthetic Cannabinoids Metabolism and Strategies to Best Identify Optimal Marker Metabolites. Front. Chem. 2019, 7, 109. [CrossRef] [PubMed]

21. Bowden, M.; Williamson, J. Cannabinoid Compounds. WO2014/167530/A1, 11 April 2014.

22. Åstrand, A.; Vikingsson, S.; Lindstedt, D.; Thelander, G.; Gréen, H.; Kronstrand, R.; Wohlfarth, A. Metabolism study for CUMYL$4 \mathrm{CN}-\mathrm{BINACA}$ in human hepatocytes and authentic urine specimens: Free cyanide is formed during the main metabolic pathway. Drug Test. Anal. 2018, 10, 1270-1279. [CrossRef] [PubMed]

23. Staeheli, S.N.; Poetzsch, M.; Veloso, V.P.; Bovens, M.; Bissig, C.; Steuer, A.E.; Kraemer, T. In vitro metabolism of the synthetic cannabinoids CUMYL-PINACA, 5F-CUMYL-PINACA, CUMYL-4CN-BINACA, 5F-CUMYL-P7AICA and CUMYL-4CNB7AICA. Drug Test. Anal. 2018, 10, 148-157. [CrossRef] [PubMed]

24. Staeheli, S.N.; Steuer, A.E.; Kraemer, T. Identification of urinary metabolites of the synthetic cannabinoid 5F-CUMYL-P7AICA in human casework. Forensic Sci. Int. 2019, 294, 76-79. [CrossRef] [PubMed]

25. Mogler, L.; Wilde, M.; Huppertz, L.M.; Weinfurtner, G.; Franz, F.; Auwärter, V. Phase I metabolism of the recently emerged synthetic cannabinoid CUMYL-PEGACLONE and detection in human urine samples. Drug Test. Anal. 2018, 10, 886-891. [CrossRef] [PubMed]

26. Mogler, L.; Halter, S.; Wilde, M.; Franz, F.; Auwärter, V. Human phase I metabolism of the novel synthetic cannabinoid 5F-CUMYL-PEGACLONE. Forensic Toxicol. 2019, 37, 154-163. [CrossRef] [PubMed]

27. Asada, A.; Doi, T.; Tagami, T.; Takeda, A.; Satsuki, Y.; Kawaguchi, M.; Nakamura, A.; Sawabe, Y. Cannabimimetic activities of cumyl carboxamide-type synthetic cannabinoids. Forensic Toxicol. 2018, 36, 170-177. [CrossRef]

28. Schoeder, C.T.; Hess, C.; Madea, B.; Meiler, J.; Müller, C.E.J.F.T. Pharmacological evaluation of new constituents of "Spice": Synthetic cannabinoids based on indole, indazole, benzimidazole and carbazole scaffolds. Forensic Toxicol. 2018, 36, 385-403. [CrossRef]

29. EMCDDA-Europol. Annual Report on the Implementation of Council Decision 2005/387/JHA. 2015. Available online: https: / / www.emcdda.europa.eu/system/files/publications/2880/TDAS16001ENN.pdf (accessed on 26 March 2021).

30. Kovács, K.; Kereszty, É.; Berkecz, R.; Tiszlavicz, L.; Sija, É.; Körmöczi, T.; Jenei, N.; Révész-Schmehl, H.; Institóris, L. Fatal intoxication of a regular drug user following N-ethyl-hexedrone and ADB-FUBINACA consumption. J. Forensic Leg. Med. 2019, 65, 92-100. [CrossRef]

31. Kadomura, N.; Ito, T.; Kawashima, H.; Matsuhisa, T.; Kinoshita, T.; Soda, M.; Kohyama, E.; Iwaki, T.; Nagai, H.; Kitaichi, K. In vitro metabolic profiles of adamantyl positional isomers of synthetic cannabinoids. Forensic Toxicol. 2021, 39, 26-44. [CrossRef]

32. Broberg, M.N.; Knych, H.; Bondesson, U.; Pettersson, C.; Stanley, S.; Thevis, M.; Hedeland, M. Investigation of Equine In Vivo and In Vitro Derived Metabolites of the Selective Androgen Receptor Modulator (SARM) ACP-105 for Improved Doping Control. Metabolites 2021, 11, 85. [CrossRef]

33. Holm, N.B.; Nielsen, L.M.; Linnet, K. CYP3A4 Mediates Oxidative Metabolism of the Synthetic Cannabinoid AKB-48. AAPS J. 2015, 17, 1237-1245. [CrossRef]

34. Nielsen, L.M.; Holm, N.B.; Olsen, L.; Linnet, K. Cytochrome P450-mediated metabolism of the synthetic cannabinoids UR-144 and XLR-11. Drug Test. Anal. 2016, 8, 792-800. [CrossRef] 
35. Zanger, U.M.; Schwab, M. Cytochrome P450 enzymes in drug metabolism: Regulation of gene expression, enzyme activities, and impact of genetic variation. Pharmacol. Ther. 2013, 138, 103-141. [CrossRef]

36. Gaunitz, F.; Thomas, A.; Fietzke, M.; Franz, F.; Auwärter, V.; Thevis, M.; Mercer-Chalmers-Bender, K. Phase I metabolic profiling of the synthetic cannabinoids THJ-018 and THJ-2201 in human urine in comparison to human liver microsome and cytochrome P450 isoenzyme incubation. Int. J. Leg. Med. 2019, 133, 1049-1064. [CrossRef]

37. Gaunitz, F.; Dahm, P.; Mogler, L.; Thomas, A.; Thevis, M.; Mercer-Chalmers-Bender, K.J.A.; Chemistry, B. In vitro metabolic profiling of synthetic cannabinoids by pooled human liver microsomes, cytochrome P450 isoenzymes, and Cunninghamella elegans and their detection in urine samples. Anal. Bioanal. Chem. 2019, 411, 3561-3579. [CrossRef]

38. Swortwood, M.J.; Carlier, J.; Ellefsen, K.N.; Wohlfarth, A.; Diao, X.; Concheiro-Guisan, M.; Kronstrand, R.; Huestis, M.A. In vitro, in vivo and in silico metabolic profiling of $\alpha$-pyrrolidinopentiothiophenone, a novel thiophene stimulant. Bioanalysis 2016, 8 , 65-82. [CrossRef] [PubMed]

39. Mardal, M.; Dalsgaard, P.W.; Qi, B.; Mollerup, C.B.; Annaert, P.; Linnet, K. Metabolism of the synthetic cannabinoids AMBCHMICA and 5C-AKB48 in pooled human hepatocytes and rat hepatocytes analyzed by UHPLC-(IMS)-HR-MSE. J. Chromatogr. B Analyt. Biomed. Life Sci. 2018, 1083, 189-197. [CrossRef]

40. Carlier, J.; Diao, X.; Huestis, M.A. Synthetic cannabinoid BB-22 (QUCHIC): Human hepatocytes metabolism with liquid chromatography-high resolution mass spectrometry detection. J. Pharm. Biomed. Anal. 2018, 157, 27-35. [CrossRef] [PubMed]

41. Fabregat-Safont, D.; Mardal, M.; Noble, C.; Cannaert, A.; Stove, C.P.; Sancho, J.V.; Linnet, K.; Hernández, F.; Ibáñez, M. Comprehensive investigation on synthetic cannabinoids: Metabolic behavior and potency testing, using 5F-APP-PICA and AMB-FUBINACA as model compounds. Drug Test. Anal. 2019, 11, 1358-1368. [CrossRef] [PubMed]

42. Kevin, R.C.; Lefever, T.W.; Snyder, R.W.; Patel, P.R.; Fennell, T.R.; Wiley, J.L.; McGregor, I.S.; Thomas, B.F.J.F.T. In vitro and in vivo pharmacokinetics and metabolism of synthetic cannabinoids CUMYL-PICA and 5F-CUMYL-PICA. Forensic Toxicol. 2017, 35, 333-347. [CrossRef]

43. Montesano, C.; Vincenti, F.; Fanti, F.; Marti, M.; Bilel, S.; Togna, A.R.; Gregori, A.; Di Rosa, F.; Sergi, M. Untargeted Metabolic Profiling of 4-Fluoro-Furanylfentanyl and Isobutyrylfentanyl in Mouse Hepatocytes and Urine by Means of LC-HRMS. Metabolites 2021, 11, 97. [CrossRef]

44. Seitzer, P.M.; Searle, B.C. Incorporating In-Source Fragment Information Improves Metabolite Identification Accuracy in Untargeted LC-MS Data Sets. J. Proteome Res. 2019, 18, 791-796. [CrossRef]

45. Anzenbacher, P.; Anzenbacherová, E. Cytochromes P450 and metabolism of xenobiotics. Cell. Mol. Life Sci. 2001, 58, 737-747. [CrossRef] [PubMed]

46. Hemmer, S.; Manier, S.K.; Fischmann, S.; Westphal, F.; Wagmann, L.; Meyer, M.R. Comparison of Three Untargeted Data Processing Workflows for Evaluating LC-HRMS Metabolomics Data. Metabolites 2020, 10, 378. [CrossRef] [PubMed]

47. Gandhi, A.S.; Zhu, M.; Pang, S.; Wohlfarth, A.; Scheidweiler, K.B.; Liu, H.F.; Huestis, M.A. First characterization of AKB-48 metabolism, a novel synthetic cannabinoid, using human hepatocytes and high-resolution mass spectrometry. AAPS J. 2013, 15, 1091-1098. [CrossRef] [PubMed] 